\title{
CULTURAL EVOLUTION, DESIGN AND PHILOSOPHY: FOR THE CHANGE OF ERA
}

\author{
C. VINIEGRA \\ Law School, Universidad Panamericana, Mexico.
}

\begin{abstract}
Human culture is the accumulation and evolution of results produced by countless design exercises. However, the process from which such design emerges lacks a solid scientific theory. Long-term sustainability issues and obsolete designs that stemmed from the Modern Era force to discover new boundaries and innovative design possibilities. This analysis starts by making reference to life's biological laws and the biophysical boundaries to which all living beings are constrained in order to propose a model that links restriction and capacity to four evolutionary strategies (Status Quo, Survival, Transformation, Growth). The latter is related to cultural evolution, which identifies human culture as a phenomenon that stays within life's general evolution. The proposed model links evolutionary strategies to the design goals chosen by people and to the fundamental philosophical blocks that are consistent with each option presented by the model. At the end a new possibility is identified for moving forward into a transformational future supported by social technologies of metabolic design which can avoid change towards an authoritarian post-modernity.
\end{abstract}

Keywords: constructal, cultural evolution, design, economics, philosophy, post-modernity.

\section{INTRODUCTION}

\subsection{Change of era}

While the modern era has been a time of advances of every kind, it has also been a period of great philosophical, political and social tension. Upon the collapse of communism in 1989, market economies and democratic political systems prevailed. Nonetheless, the success of market economies is incomplete due to the persistence of ancient issues such as curable diseases, social marginalization and wars. At the same time, human kind faces new challenges because of the deterioration of the environment, changes in climate conditions of the planet, exhaustion of key resources such as farming fields and clean water, along with the growth of social pathologies such as addictions and new violence phenomena that range from the family to the work environment. Regarding the ancestral issues, their persistence in the 21 st century makes many people think that they are inevitable sufferings. When thinking about the new issues, decades of strategies aimed to solve them have accumulated and results are opposite of what it was expected.

In terms of what appears to be working best, such as developed markets, the world's fast technical transformation has undermined the paradigms of political and economical organization. Governments try to adapt unsuccessfully to a world that decentralizes very fast and where it is no longer easy to identify rights and obligations of a society that operates globally. In businesses, profit margins disappear in many sectors due to the quick commoditization of products, and intellectual property rights protection becomes irrelevant when competitors arrive to the market before the one who actually develops a product.

These are times where there is the ever present feeling that a crisis is about to burst, and the provision of ideas is insufficient to explain or solve even one important issue at its root.

Due to the recurrence of crisis of all types and to the probable perspective of disasters, such as a climate change that can create among other things hunger and massive migration of people, it has become necessary to review the way in which we design human culture. 
For the time being, there is not a wide consensus on what can happen or what should be done to avoid any negative scenario. Moreover, the expectations range between apathy and an overflowing optimism and anguish for perspectives that could generate the end of the human civilization. This means that decisions made on a short term, will remain with a high level of uncertainty and debate.

\subsection{The greatest challenge}

The nations of the world since 1992, through the United Nations Framework Convention on Climate Change (UNFCCC) and supported by ample scientific consensus, have been unsuccessfully trying to build an agreement to limit greenhouse gas emissions. The impossibility to reach such an agreement, that from a rational point of view should not be so complex, points to various questions that modern philosophies have not been able to respond.

The first of these issues is to recognize that most of modern technology is aimed at maximizing value through the satisfaction of consumer's needs while generating benefits to the producer. However, it does so recognizing that price formation lacks the incorporation of negative externalities. Although in many cases it is possible to generate valuable transactions to consumers and producers at a lower cost with the additional benefit of an important reduction of negative externalities, as shown below.

Figure 1 known as Mckinsey curve [1] shows the existence of situations where the incorporation of negative externalities to a price can produce cost savings at medium or long term, here rationality assumptions in the decision making process fail. On those cases where economic agents prefer to take on higher costs.

In a case where the incorporation of externalities to the price means higher costs in economic transactions, agents, usually and rationally make 'downstream' transference of negative externalities. The latter is done assuming, even on a globalized world, that it is possible to transfer externalities to a different place within the closed system known as biosphere.

Related to the transfer of costs by externalities, there is the phenomenon of generation of negative social externalities for those downstream whose possibilities for development are hindered.

Based on the above, it can be said that the greatest challenge for energy, climate preservation and economic development agendas is to decide whether the design criteria for politics, economy and relationship among nations will be:

1. A hopelessly limited world or;

2. An aspirational world oriented towards eliminating the maladies that affect the human kind.

It must be understood that an evaluation mistake in one way or the other will mean, in the first case, building a restricted model around wasted possibilities. In the second case, the pursuit of an aspirational model that would drain out limited resources.

\subsection{Mind sciences revolution}

Mind sciences or cognitive sciences are a set of disciplines focused on the study of human intelligence and consciousness. It includes specialized fields such as psychology, philosophy, neurosciences, linguistics and artificial intelligence, among others.

Issues and dissatisfactions present at end of the modern era produce the need to understand the main actor, since behaviours, ideas, needs, and perceptions with which the world is built, emerge from people and their minds. It is not by chance that new fields like evolutionary economics, behavioural 


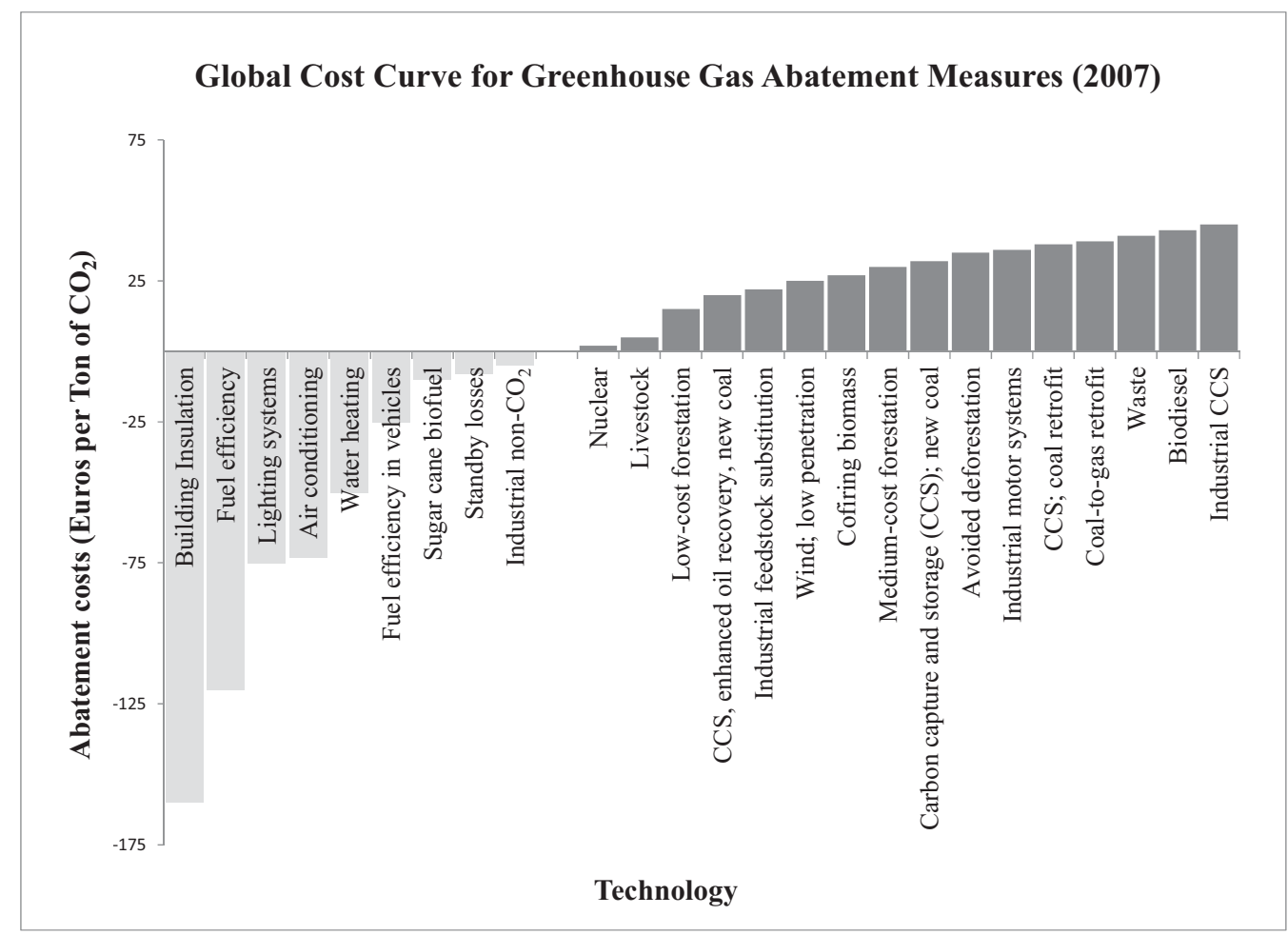

Figure 1: A cost curve for greenhouse gas reduction. Made with data taken from Ref. [1]. Also known as the curve of abatement costs of gases with greenhouse effect, curve of potential energy efficiency, curve of 'no regrets', or Mckinsey curve. The y axis shows the costs of abatement for different technological choices. It also shows that there are many costnegative options (those below 0 on the $\mathrm{x}$ axis).

economics and evolutionary psychology have been developed recently in order to try to reach solutions for old and new issues. In fact, almost all of these new disciplines found sources of inspiration in mind sciences and genetics. The latter have had an important development through the convergence of revolutions in computer science, biology and physics [2].

In order to introduce the reader to approaches originated in mind sciences, below there is a conclusion from the work done by Gerald Zaltman [3].

Zaltman points out that it is only possible to understand the world through the relationship that people maintain with the environment through their senses. In other words, ideas are intimately related to the information gathered by experience. The latter implies that experience is correlated and added by the mind to make up structures known as metaphors, which in turn act as the construction blocks of cognition that constitute the concepts and ideas with which human culture is shaped.

As an example, Zaltman tells how the human being on the first months of life, given his physiological constitution and low development level, must achieve biped locomotion with the added difficulty of having a disproportionately big head that rises the centre of gravity away from the floor. This unavoidable reality forces the mind to translate environmental information through the internalization of concepts and rules (force of gravity, inertia, lever and balance), known in formal 
physics as classical mechanics, into concepts that are used to coordinate locomotion without having to resort to dozens of rules every time that movement is required.

The example results in the formation of the 'balance metaphor' which, by being central in man's survival, is embedded to other aspects of life such as the desire to attain balance in the physical and psychological environment that surrounds a person.

Besides the balance metaphor, he discovered through experimentation that a great deal of desires, ideas, fears and aspirations are framed by a reduced number of metaphors, what he calls deep metaphors. The author has also demonstrated that in cultural contexts where some elements of sensory experience are missing, the interpretations related to concepts that some might consider universal, are different [4]. This indicates that the human mind can only explain the world through concepts and cognitive structures built by information gathered through experience and that it is unable to construct concepts that are not linked consciously and to a greater extent unconsciously to the sensory experience.

\subsection{Assumptions and working questions}

\subsubsection{Assumptions}

1. The human being is circumscribed to the biological rules that make life possible.

2. There is a possibility of a significant change in culture design (change of Era) due to the exhaustion of designs upon which modern culture has been built.

3. Sensory experience makes possible the creation of concepts over which human cognition is built.

4. The environmental scenario is adverse in the future.

5. Humans are capable of having a rational and conscious relationship with others and with nature.

\subsubsection{Questions}

1. Do human beings meet boundaries in the ontology within their reach by cognitive structures associated to the information perceived in their close relationship with the fundamental laws of life?

2. If biology limits human's ontological boundaries, how are the design goals people use affected?

3. In a scenario of severe environmental deterioration, what design approaches would work? What would be the design requirements?

\section{LIFE'S LAWS, THE HUMAN BEING AND DESIGN}

\subsection{What is life?}

In the first place, it is important to differentiate between two questions, what is life? and, what is life for? For it is possible to answer the first question, while solving the latter falls outside the realm of this document. In that light, it can be said that life is the process in which a finite amount of matter self-organizes, metabolizes (uses energy from the environment), grows, reproduces and evolves [5].

\subsubsection{Self-organization}

According to the second law of thermodynamics, every system tends to entropy or disorder to the point where it is no longer possible to keep it working. Taken to an extreme, the second law of 
thermodynamics shows the possibility that, as time passes, the entropy of the universe will increase to the point where even matter will lose cohesion.

In spite of what was just described, the process of life generates higher levels of order [6] by importing negative entropy for itself, also known as negentropy or syntropy [7]. However, it is done by exporting a larger amount of entropy to the environment, resulting in a net increase of entropy in the universe, all in accordance to the laws of thermodynamics.

In the aforementioned thermodynamic exchange, life augments order in a process called data exchange [8]. In it, energy obtained from the environment is used through metabolism to organize molecules in coherent sequences of information, known as genetic information. The by-product of this process is heat release or the exchange of entropy to the environment.

\subsubsection{Metabolism}

The process of life is only possible within the boundaries of the second law of thermodynamics where the generation of higher levels of order or information exchange, requires energy use and dissipation of heat, both exchanged from and to the environment; in this process, the cells from all living beings, for each rise in their capacity to exchange information, must increase the capacity to dissipate heat, so size and complexity of cells are limited by physics laws. The cells that go beyond the mentioned threshold are self-destroyed.

\subsubsection{Growth}

Smaller and larger cells of live matter are found in the physical boundaries allowed by thermodynamics and the size differential is balanced through: (a) the speed with which energy is processed (metabolic rate) and (b) the capacity to disperse heat (entropy). This means that as the size of the cell changes, the metabolic rate or the amount of used energy together with the amount of information that a cell can process vary according to Kleiber's Allometric Law of Scaling [9]. This is the reason why all living beings use less energy per equivalent mass unit as size increases. Nevertheless, the rise within the organization level means increase in net consumption of energy and volume of individuals.

For this reason, a kilogram of bacteria uses more energy than an equal amount of elephant's biomass; however, a single elephant consumes more energy than a bacterium and has access to higher levels of order (negentropy) and information exchange than the bacteria, while it also exports more entropy to the environment.

\subsubsection{Reproduction}

In accordance to thermodynamic laws, living beings deteriorate over time and, with deterioration, life eventually disappears. There is no knowledge of anything alive that does not tend to die. Nonetheless, the phenomenon of life, through the genetic mechanisms of reproduction, inherits an updated copy of its genetic information to a new being whose entropy is low and thus this enables the continuity of the process.

The update of genetic information occurs during the ascendant's lifetime through external influences that generate mutations and by newly discovered mechanisms of activation and deactivation of genes that respond to environmental stimulus. The subject that studies the influences of the environment over genetic activation is called Epigenetics.

Even though all living beings will die, when defining the guidelines by which life operates, the first one is that in spite of being circumscribed to the universal laws of physics, life uses everything within its reach to be continuous through time.

In fact, it can be said that through the reproduction mechanism, the information from the first living beings persists over time through their descendants. The latter spans a temporal space measured in 
millions of years. That is why the deoxyribonucleic acid (DNA) or the molecule of life can be called the immortal molecule as long as there is life in the universe.

In the reproduction process of living beings, two different strategies can be observed, explained under the 'r/K Selection Theory' [10].

Living beings oriented towards an $r$ reproduction strategy exist in unstable environments and nonsaturated ecological niches where high speed of reproduction is crucial for survival. The characteristic features on this strategy are low energy investment to the descendants and high fecundity, low body volume, early maturity, short life expectancy and wide dispersal of the population. Rodents are a mammal example. Scientific literature points $r$ selected species as opportunists.

Living beings oriented towards a $\mathrm{K}$ reproduction strategy exist in stable environments and niches close to their maximum load capacity; their fecundity rate is low, energy investment from parents to descendants is high, maturity is slow and life expectancy is long. Big mammals are the main examples of species under K selection. Scientific literature points K selection species as balance species.

\subsubsection{Evolution}

The physical margins where life is possible seem small, but there is enough room within them to generate adaptation needs [11]. These are covered in the genetic traits that persist or get discarded through the reproduction process.

Regardless of the fact that the most popular interpretation on Darwin's proposition, the survival of the fittest, points toward survival of the biggest, strongest, and fiercest, the most accepted interpretation on Darwin's work is that fitness should be understood as the selection of genetic features that guarantee, on the long-run, the survival of the best adapted [12].

As an example, it can be said that in similar environments, discounting energy availability, living beings with high metabolic rates will be better adapted when energy is abundant and, given that abundance, it may be necessary to compete in a numerous population. On the contrary, in an environment with low energy availability, living beings with low metabolic rates and greater willingness to collaborate will be more successful [13].

\subsubsection{Restriction and capacity}

Life is limited by thermodynamics. It relies on the environment to obtain energy, given the opportunity, it widens its capacities to accumulate negentropy and responds to environmental changes using the evolution mechanism. In this light, one may conclude that there are two working axis that determine the success or failure of the changes and their persistence through time.

\section{Restriction. The environment, the external.}

The list of environmental variables that affect living beings is long, but the one that controls total growth is the scarcest, as stated by Liebig's Law of the minimum [14] we can also state that the most bounding resource is energy. Be it autotroph living beings and solar energy, or heterotroph beings and their food. The environment in which living beings develop may be of low or high restriction; there is no way anyone can say that there is an unbounded environment since. In spatial terms, life shares a finite environment known as Earth and it is not possible for it to survive isolated in the average conditions present outside the planet.

Capacity. What is of each, the intrinsic.

If at any moment there was no life and by life's existence, in spite of the higher transfer rate of entropy towards the universe, a greater order is produced in its operating range, on a long term and as a second directive of life: life works to widen its possibilities of information exchange or negentropy accumulation. At the limit, life will achieve as much order as the available energy and entropy level of the environment will allow [15]. 
The dependence on the environment and its changes produce exchanges among the time permanence directive versus the capacity to generate negentropy (negentropic capacity) directive. The latter prevents that the speed in which life spreads through the environment to be constant since changes in the environment and restriction levels, define the necessity to modulate the evolution process in order to guarantee permanence in time.

The acceleration on capacity growth will require larger amounts of energy, either due to an increase in population or to an increase in the complexity of the living beings that are part of the process. However, in spite of the irrevocable calling of life to generate as much order as possible, the speed to do it will vary in time as a function of the acceleration and deceleration of the capacity to generate negentropy.

\subsection{Metabolic model}

This paper has described the features of living beings, biological and physical laws that limit them and two axis of action, restriction and capacity (Fig. 2). In that light, and using the environment as the external and capacity as the internal or what is intrinsic to life, it is possible to make a schematic analysis of the gathered elements in a metabolic model generated by the intersections of each category.

Quadrant 1: Low restriction/Low capacity: Status Quo. On these coordinates, available resources supplied by the environment surpass the metabolic needs of the population. The environment is unstable either by reproductive competition and/or environmental variations. Additionally, there is no change in the capacity to generate negentropy. The reproductive rate is maximized but given the low negentropic capacity of the population, the resources' consumption rate is lower than the environment's replacement rate.

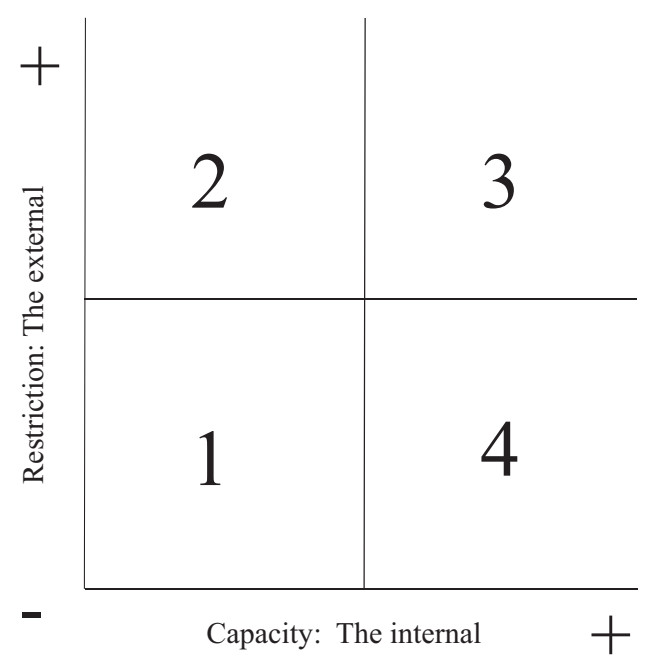

Figure 2: The visual representation of capacity versus restriction where the cartesian plane is broken into four quadrants by separating each category into low and high. This type of representation is commonly referred to as a 'magic' cuadrant. By mixing every possibility the resulting cuadrants are: 1 . Low capacity and low restriction, 2. Low capacity and high restriction, 3 . High capacity and high restriction, 4. High capacity and low restriction. 
Quadrant 2: High restriction/Low capacity: Survival. On this quadrant, the energy availability is compromised and there are no chances for expansion due to the impossibility to increase negentropic capacity. In metabolic terms, all energetic non-essential pathways disappear and energy use rate is minimized. If the environment's replacement rate is over-run, there is a reduction of population or death.

Quadrant 3: High restriction/High capacity: Transformation. The shortage of resources is compensated with an accelerated growth in negentropic capacity to take on new opportunities. There are potential but not present threats; every new function is enabled to seize a new opportunity within the environment.

Quadrant 4: Low restriction/High capacity: Growth. High availability of resources allows the colonization of the environment. It is possible to increase the negentropic capacity and the metabolic rate at the same time. Competition is produced by population's increase and metabolisms that consume more energy are favoured.

\subsubsection{Hemispherical analysis of the model}

By dividing the plane into four sections with two lines one vertical and another horizontal, the resulting hemispheres will be: vertical cut, left and right hemispheres; horizontal cut, top and bottom hemispheres.

Vertical

Left. Low degree of evolution and capacity. Environmental conditions overcome life's long-term evolutionary dynamics, options are limited. Negentropy generation is limited.

Right. High degree of evolution and capacity. The long-term dynamic for capacity growth, works unbounded in any environmental conditions. Negentropy's generation grows, as well as energy use and the exchanged entropy with the environment.

It must be noted that the definition about what is a high or low degree of evolution remains an open discussion in biology. Higher evolution can be understood as: (1) Distance related to origin (e.g. embryonic development stages) or (2) Complexity on shown behaviours and (3) Possibilities of epigenetic activation or deactivation.

\section{Horizontal}

Top. There is little waste of energy, cooperation prevails over competition. The challenge imposed by the environment is more important than rivalry, thereby metabolism is optimized. In addition, efficiency levels used to incorporate energy to life process are increased. On the reproductive side, selection is oriented towards ' $\mathrm{K}$ ', there is low variation in environmental factors and low rivalry level.

Bottom: Energy use is maximized; competition prevails over cooperation; reproductive competition is more important than the environment's challenge. Efficiency is not important, but final metabolic capacity is. Reproductive selection is oriented towards ' $r$ '; there is instability due to environmental factors and/or because a high degree of rivalry.

\subsubsection{Stability and instability in the quadrants}

In order to complement the analysis, each quadrant is divided into two sectors, one stable and one dynamic (see Fig. 3 and Table 1) to indicate that when undetermined thresholds are crossed over within a quadrant, the strategy will be stable; if thresholds are not crossed over there is a situation of instability and the possibility of a change of strategy.

For quadrant ' 2 . Survival', the stable sector is death, so permanence is only possible in the dynamic or unstable sector. 


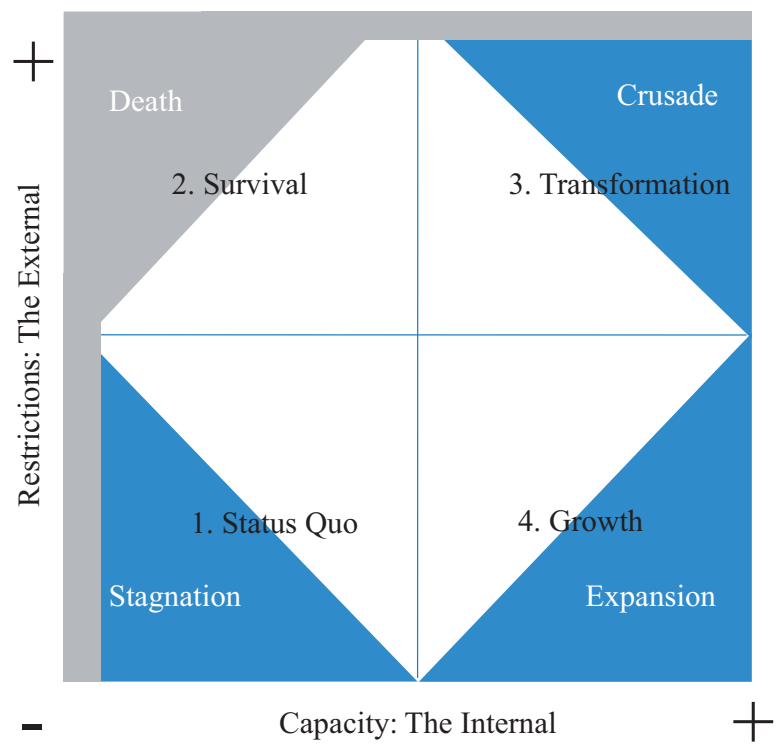

Figure 3: The same representation of Fig. 2 is used with the addition of the stable subsectors explained in Table 1. To denote that within each quadrant there is the possibility of stable strategies when the parameters of restriction and capacity are strong enough. Special consideration should be taken for the stable subsector 'Death' to note that at some thresholds of restriction and lack of capacity life ends.

Table 1: Quadrants and stable sector description.

\begin{tabular}{llll}
\hline$\#$ & Quadrant & Stable sector & Description \\
\hline 1 & Status Quo & Stagnation & $\begin{array}{c}\text { There is no change, there is no evolution, there is } \\
\text { no external aggression, and there is stability } \\
\text { Surviving thresholds are overtaken due to a } \\
\text { combination of low capacity and high } \\
\text { restriction. Life is not possible } \\
\text { Evolution process is maintained; not giving up on } \\
\text { capacity growth, with high restriction, means } \\
\text { consecution of a purpose or telos } \\
\text { It is the unlimited growth scenario, the environment } \\
\text { is colonized, and capacity grows }\end{array}$ \\
\hline
\end{tabular}

\subsubsection{Ecological niches in the model}

To start making the link to the questions that give rise to this paper, categories that make reference to different types of living beings and the ecological niches they hold within the general model will be addressed while explaining Fig. 4. 


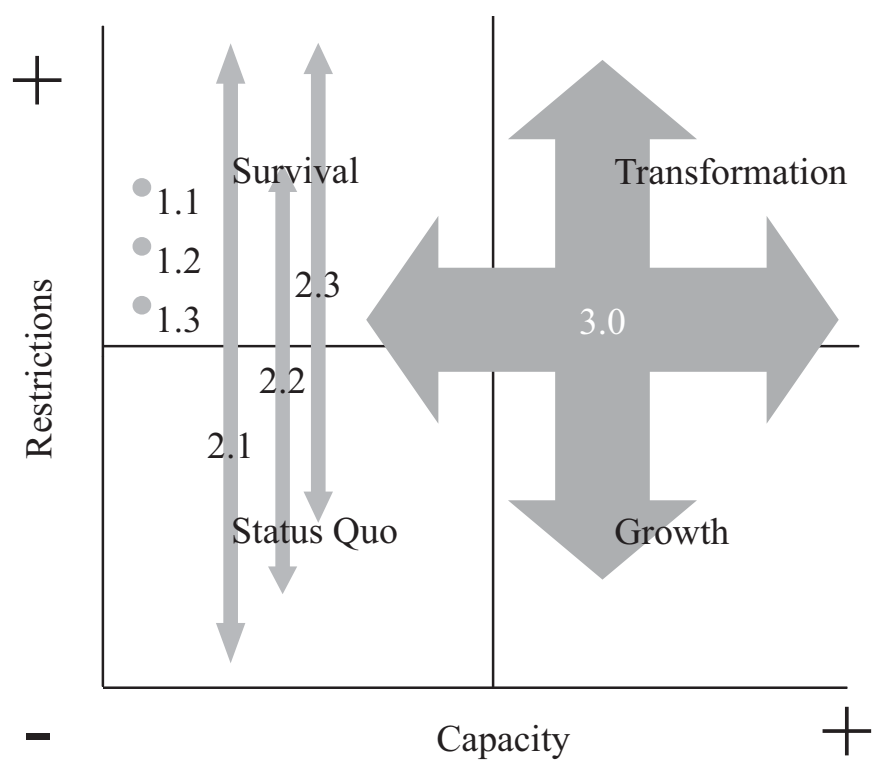

Figure 4: Graphic representation of how ecological competition within the model works. Points 1.1, $1.2,1.3$ represent the possible survival strategies for some heterotrophs, all within the same capacity line. Lines 2.1, 2.2, 2.3 represent survival spaces enabled by locomotion but restricted to a single capacity line. Arrows 3.0 show humans that by becoming free from hardware evolution and advancing into Cultural Evolution became able to use and choose any survival strategies.

\section{Autotroph}

They populate the different restriction levels by differentiation of species, there is no locomotion or behaviour, in Fig. 4 a species is a point, the whole forms a negentropic capacity line (photosynthesis). They evolve through physical features or 'hardware' (Points 1.1, 1.2, 1.3 in Fig. 4).

Non-human heterotrophs

They acquire the capacity so that each species populates a vertical line and, through locomotion, they generate a new adaptation strategy: migration, which means capacity to run away from danger, attack, pursue pleasure (instinct); behaviour emerges and is always closely related to 'hardware' configuration. They manage to settle on new capacity spaces by differentiating their energy strategy: herbivorous, carnivorous and omnivorous. They also evolve through 'hardware'. Locomotion accelerates evolutionary competition (lines 2.1, 2.2, 2.3 in Fig. 4).

Human heterotrophs

They abandon evolution by 'hardware' (physical features), and represent a new evolutionary strategy for life, evolution through 'software'. They are capable to choose any quadrant, be it by migration, aversion to pain, attraction to pleasure and by cultural development. They have the ability to choose their behaviour, which adds extra capacity mechanisms and information to the ones granted by genetic inheritance. They manage to change the pattern resource usage in a quick way through a new mechanism, cultural evolution [16]; that is inherited to their descendants through knowledge transmission (cultural reproduction) which means the accumulation of negentropy in culture (arrows 3.0 in Fig. 4). 


\subsection{Cultural evolution}

In biological terms, the human being is close to the extreme of ' $\mathrm{K}$ ' selection within the reproduction strategy. This means that it improves his descendants' survival possibilities by investing in them a great amount of energy. ' $\mathrm{K}$ ' selection also means that there is a long maturity period for individuals and a longer life span.

Unlike some species under ' $\mathrm{K}$ ' selection, such as elephants and whales, the human being does not have great body volume or exceptional physical capacities, but it consumes huge amounts of energy. As stated before, the main difference on man's survival strategy lies within the reduction of physical and genetic competition with other species, in order to evolve quickly through a new strategy already defined as cultural evolution.

Exactly like genetic evolution, cultural evolution generates negentropy through the use of energy exchanged for higher levels of information expressed in knowledge, art and technology. Furthermore, just as it happens on genetic evolution, new levels of information (knowledge) generate new possibilities to access energy sources and for new ways to make use of the environment (technology). The latter is done in a way similar to what happened when energy strategies like the herbivorous, the carnivorous, and the omnivorous appeared. In Philosophy, a rise in the understanding of the universe is defined as an increase in the consciousness level or approximation to the truth. In Biology, the difference between conscious (man) and unconscious beings (the others) is also pointed out.

Even though the theme of consciousness is one of the most debated points in religious theology and secular philosophy, both approaches point at the need to answer the main ontological and cosmological questions: What exists? What is life for? Is the universe infinite? Does time have a beginning and an end? What is the essence of matter? It may be presumed that whoever manages to obtain an answer to any of these questions would be on a higher level of consciousness that those who don't.

Making definitions based on features that separate unconscious animals from conscious man has become complicated since Ethology reports more complex behaviours in animals than the ones assumed before (i.e. chimpanzee's use of tools, cooperation actions, learning and problem solving within various species, etc.) while neurosciences acquire better understanding of the human brain and report higher intervention of the subconscious in people's actions and motives than ever imagined.

Therefore, it is possible to say that the gradient going from the inert to the subconscious and to the conscious is related to the non-living, life and life's level of organization according to the capacity to generate negentropy. This positively correlates energy use and the level of consciousness, where the effective use of energy (energy efficiency: useful work/energy consumption), is more important than total use of it.

\subsubsection{Energy and human development}

Figure 5 shows primary annual energy supply per capita in the world (year 2007), grouped by geographical regions and expressed in tons of oil equivalent (ToE).

In terms of cultural evolution, the complement to energy consumption is shown through the comparison (Fig. 6) of human development index (HDI) [18] with the total energy supply, measured in ToE units per capita. This comparative analysis shows that in those cases (126 countries) with available information, developed countries with HDI rates higher than 0.9 are the ones that use more energy.

Cultural evolution also keeps the relationship between increase in capacity and energy efficiency. As an example, it is pointed out that boiling water on a bonfire and walking use more energy than 
Energy Demand and Dependance

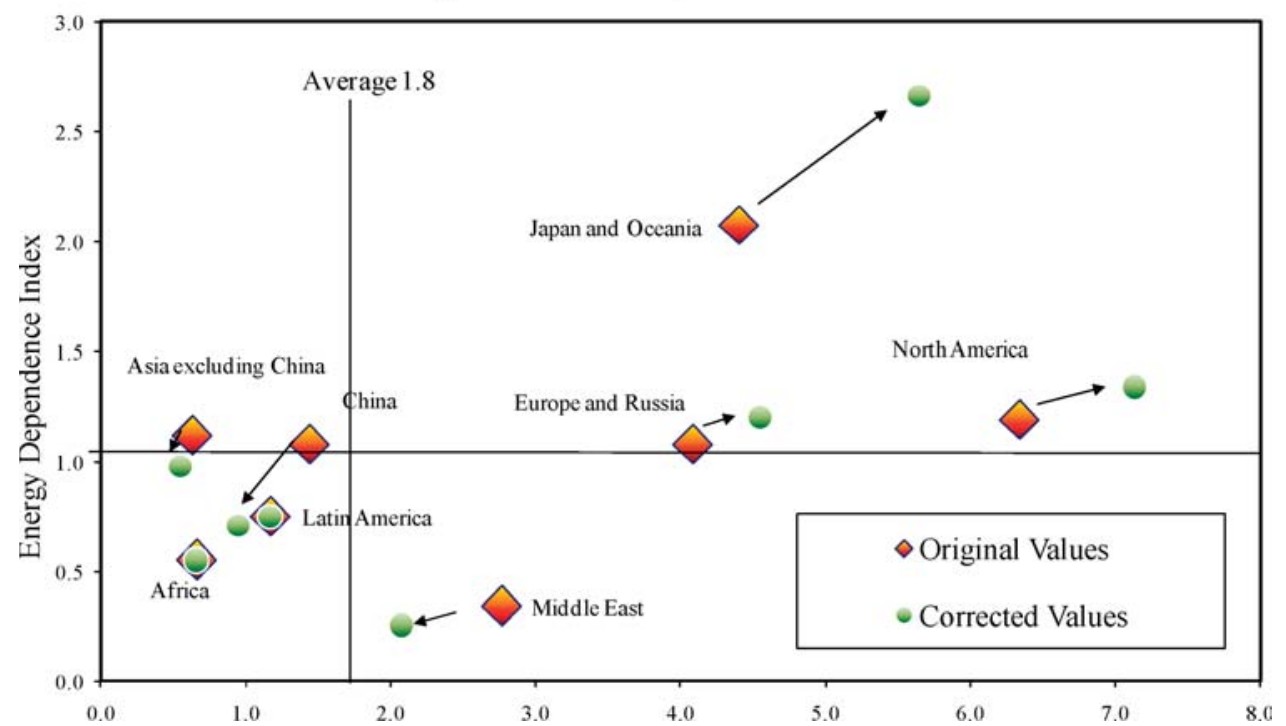

Figure 5: High and low energy consumption regions per capita; the movement among original values and the corrected ones, represent the effect of energy transfers, not accounted for on energy statistics, that changes location virtually through international trade [17]. As regions have higher consumption rates, they also are more energy dependent (Energy dependence is equal to: Total Energy Supply/Production) from the other parts of the world. Virtual energy transfers and energy dependence is one of the problems that impede progress on climate change negotiations.

boiling water on a stove and covering a mile by car. If data are compared on equal units, however, whoever cooks on a gas stove and uses a car or even travels by plane, does more. In other words, more water is boiled, more miles are travelled, at a higher speed and with heavier vehicles. The latter is similar in evolutionary terms, with living beings that have a high metabolic rate but consume few resources per capita versus living beings with low metabolic rates that consume lots of resources per capita (Image 1).

\subsubsection{Empirical analysis}

So far, there is no study designed to overcome methodological barriers within current energy statistics. But with available data, it is possible to make an empirical approach to the following question: In cultural evolution: Is Kleiber's scaling law, or any other, applicable?

In order to make an evaluation of nations according to the proposed metabolic model, the chosen variables are:

Capacity $=$ Patents a year/Million inhabitants. Intellectual property databases are repositories of new cultural activities that depend on the historical accumulation of knowledge. Unlike indicators focused only on scientific production, patents are designed to generate economic value through the satisfaction of a unattended need in the market. For the purposes of this paper, the public database of the patents' office of the United States of America (USPTO) was consulted at www.uspto.gov, to obtain the total registered patents by country during 2008. It resulted that only 75 countries have a 


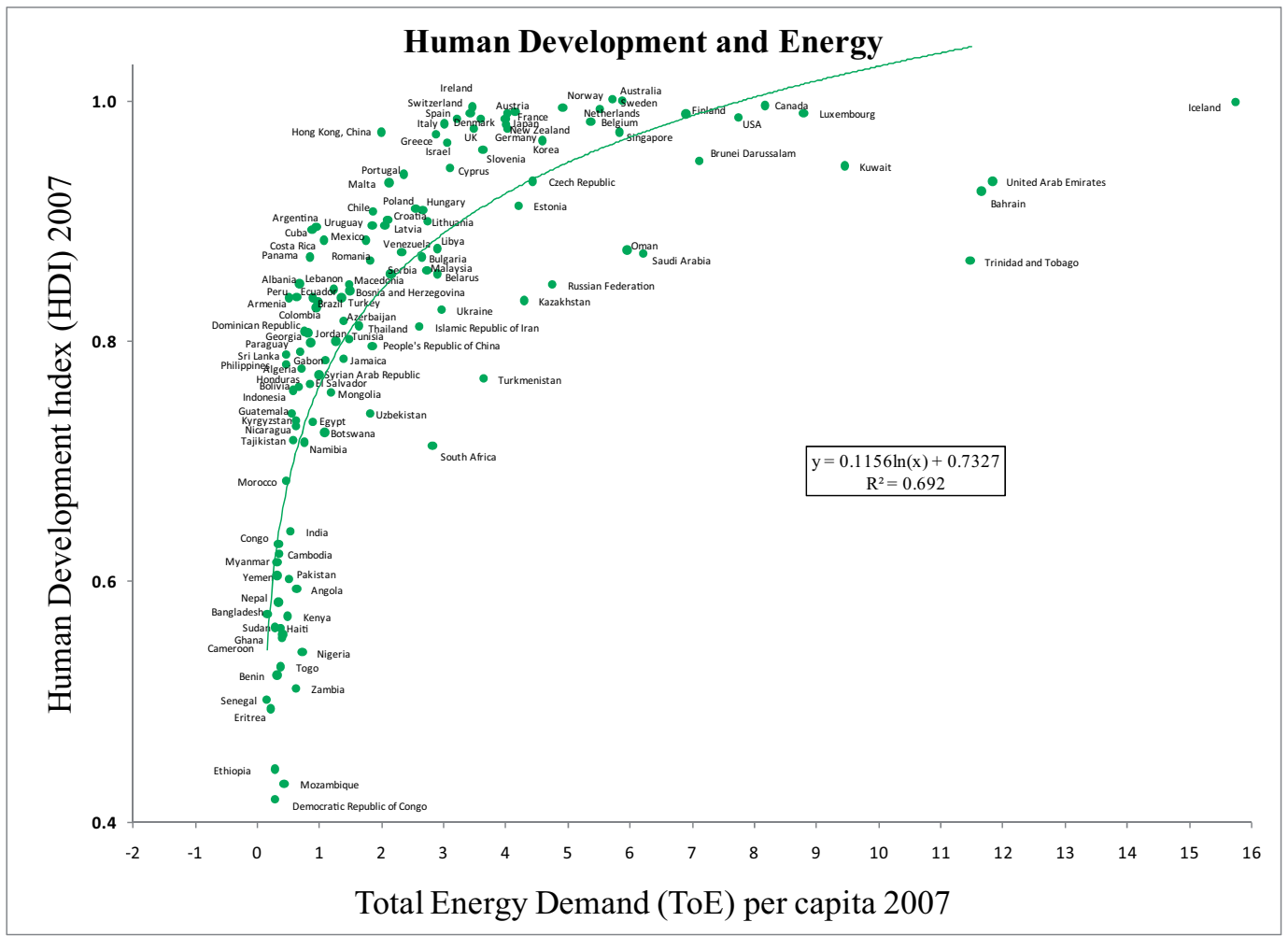

Figure 6: Human development and energy demand. Source: HDI, United Nations Development Programme (www.undp.org), Total Energy Demand, International Energy Agency (www. iea.org). ToE, Standardized unit equal to the amount of energy obtained through the combustion of a ton of crude oil. It is equal to $41.868 \mathrm{GJ}$ and to $11.63 \mathrm{MW} / \mathrm{h}$.

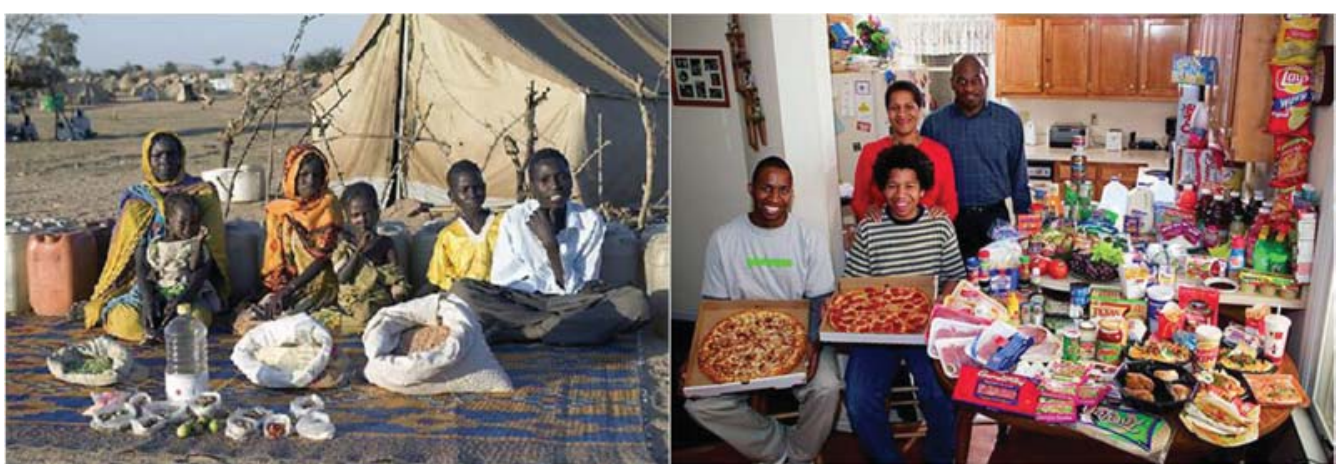

Image 1: From the book Hungry Planet: What the World Eats @2005 by Peter Menzel and Faith D'Aluisio. Images present a photographic study of families from around the world, revealing what average families ate during the course of one week. http://www. menzelphoto.com/books/hp.php 
patent assigned to any of their citizens during that year. The patents' total was obtained in searches where the field 'assignee country' matches any of the countries in the catalogue published by the same USPTO.

Restriction = Energy supply per capita (ToE/inhabitant). Supply and demand for energy per capita, regardless of any production level, represents an economy's internal usage of energy. Energy balances, which are the information source used for this analysis already, have imports and exports accounted for. Consequently, the figure 'total energy supply per capita' may be used as an indicator of internal energy 'restriction' availability in an economy (see Box 1).

Regardless of negative economies of scale on energy costs related to the increase on the human development index (energy consumption grows faster than human development index) shown in Fig. 6, the graph's interpretation must be noted since the way in which energy statistics are constructed has several problems (see Box 1). It must be taken into account the unequal participation of countries in the development of modern culture.

Figure 7 shows the relationship of patents' production per million inhabitants versus annual energy supply per capita. It is easy to observe that cultural or negentropic contribution of a society (patents) grows faster than the energy demand. In this example, a change of scale is visible when consumption per capita is higher than three ToE (gray line in Fig. 7), since only countries that exceed that consumption generate more than 10 patents per million inhabitants a year.

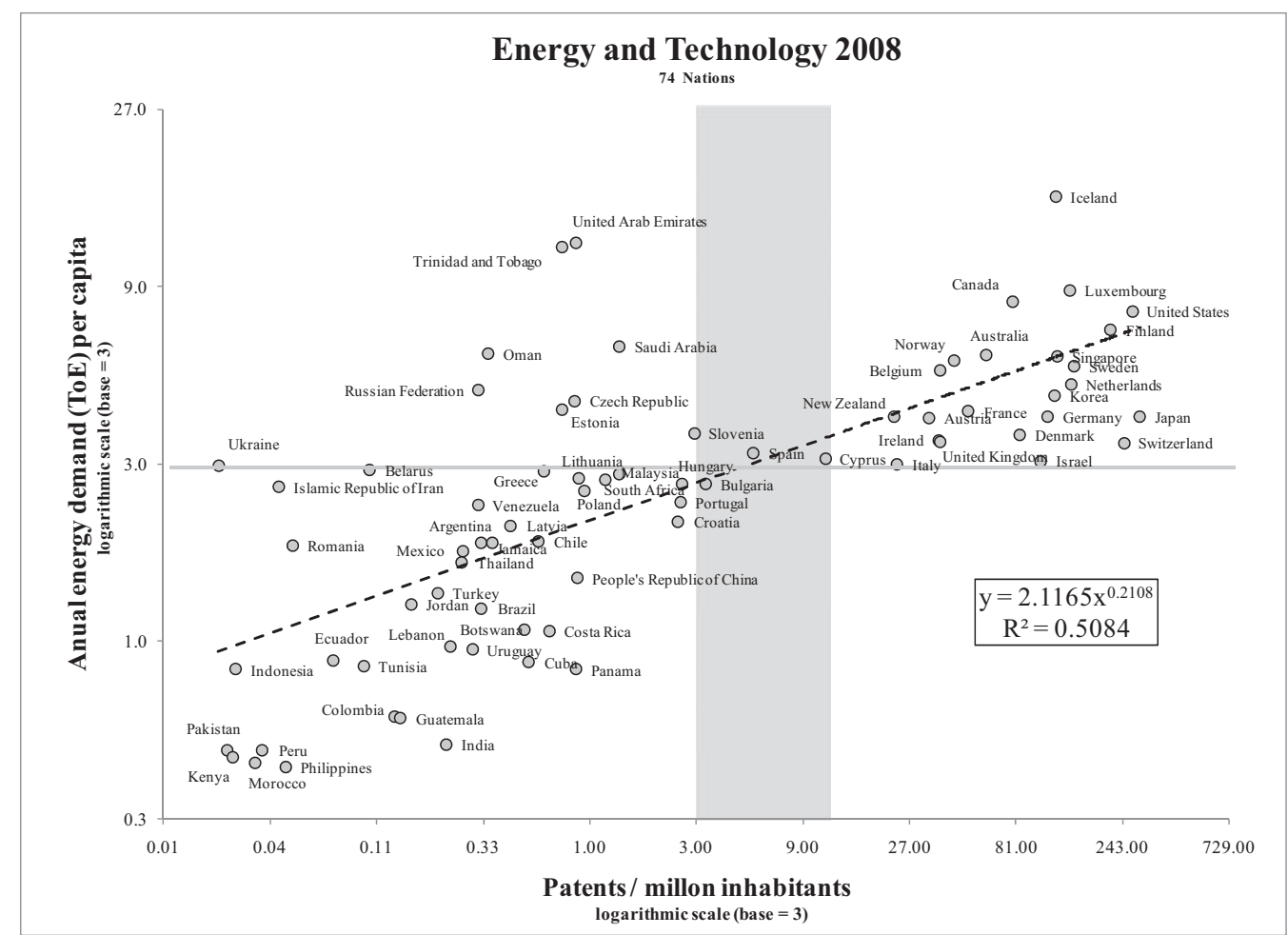

Figure 7: Energy and technology. Source: Energy International Energy Agency (www.iea.org) and patents from U.S. Patent Office (www.uspto.gov). 
Regarding what was said above, the equation with better adjustment by a potential model $(\mathrm{y}=$ $2.1394 \mathrm{x}^{0.2108}$ ) does not present a high variation coefficient $\mathrm{R}^{2}=0.5084$, but it is enough to show a scaling behaviour (energy/patents) lower than one, which means that patent production grows faster than per capita energy consumption.

In levels lower than three ToE per capita, the annual patents' indicator per million inhabitants is lower than one. The shadowed region that covers from 2 to 10 patents a year/million inhabitants is the transition zone between development scales and contains countries under change process, from underdevelopment to development.

In Fig. 7, it can also be seen that as the defined variable to evaluate capacity (patents/million inhabitants) increases through various magnitude orders that range from 0.1 patents a year per million inhabitants, up to more than 200, developing countries get clearly separated from developed ones. It is worth noting that there is not a single case of a developing country with low energy consumption and high patents' registration rate.

The aforementioned is supported by the case of countries with low rate or efficiency in the (patents/ energy) ratio, but that exceed an annual energy consumption of three ToE per capita, such as The United Arab Emirates, Trinidad and Tobago, several oil exporter countries and some ex soviet ones. In spite of making modest contributions to technological development, less than one a year per million

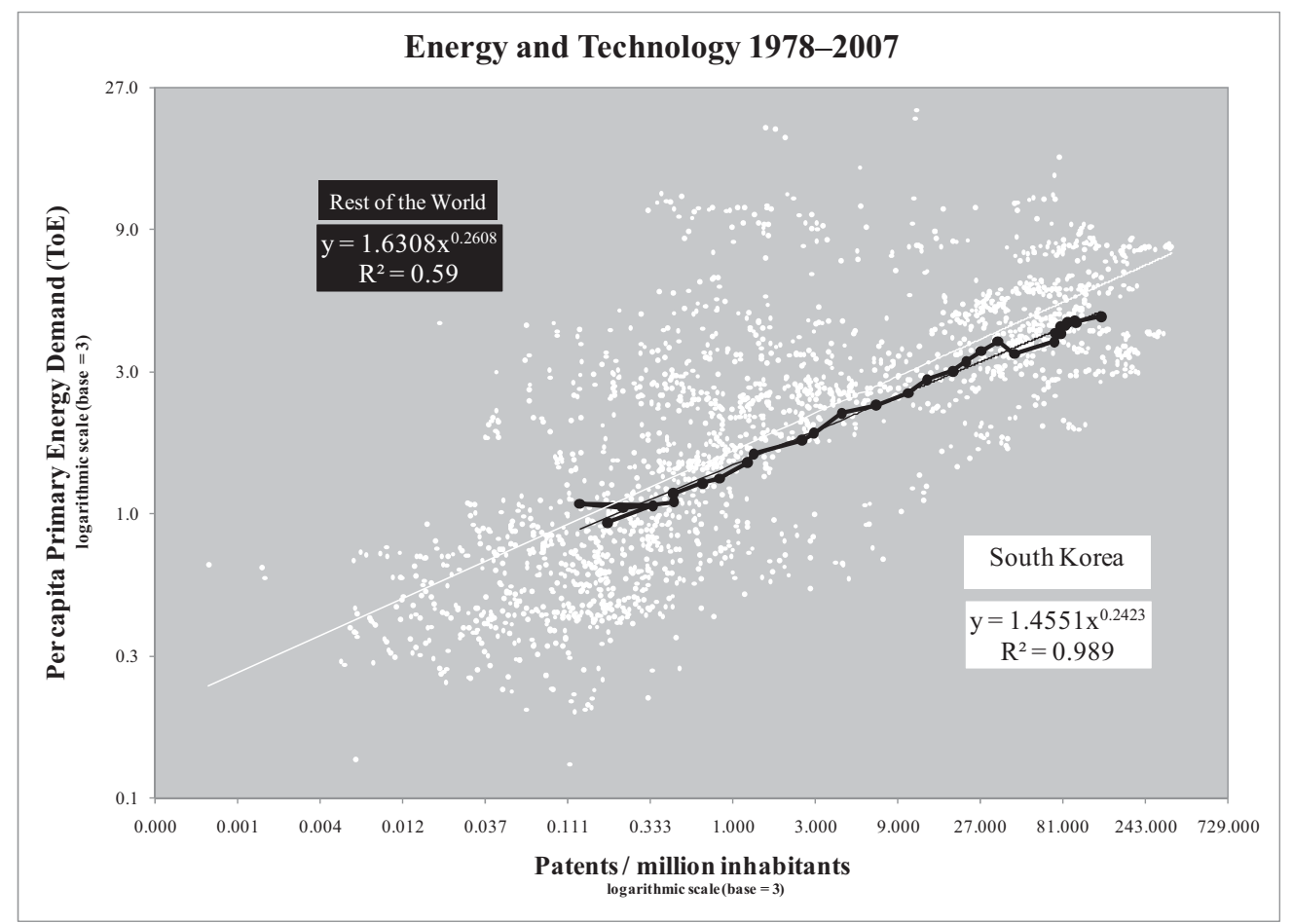

Figure 8: Evolution of energy and technology from 1978 to 2007. South Korean performance is indicated in black with a correlation function $\mathrm{y}=1.4551 \times 0.2423\left(\mathrm{R}^{2}=0.989\right)$. Source: International Energy Agency (www.iea.org) and patents from U. S. Patent Office (www. uspto.gov). 
inhabitants, the lower capacity limit is not less than 0.33 patents a year per million inhabitants. Number that is higher than that of many underdeveloped countries.

The most suggestive aspects in Fig. 7 are the empty spaces at the left top and right bottom quadrants. Empty spaces indicate possible borders, top and bottom, of a scaling rule between energy use and development. In fact when all points (2115) from a database with a dataset from 1978 to 2007 were plotted (Fig. 8) and analyzed with a potential model, the result was a regression equation equal to $y=1.63 x^{0.26}$, with a variation coefficient $R^{2}=0.59$, where ' $y$ ' is equal to primary energy supply in ToE units and ' $\mathrm{x}$ ' is equal to patents registered in year per million inhabitants.

After making a diachronic analysis with an online tool named 'Motion Chart' from 'Google Docs', it was observed that the nation with best performance, and the only one that advances several orders of magnitude in both axis is South Korea. A nation that frequently is referred in specialized publications as an example of success given the fast achievement in economic and social development.

For this reason, a specific analysis was made only with South Korea's data, also presented in (Fig. 8), where it the following results are observed: $y=1.45 \mathrm{x}^{0.24}$, with a variation coefficient $\mathrm{R}^{2}=0.98$, where ' $y$ ' equals to primary energy supply in ToE and ' $x$ ' equals to patents per million inhabitants per year. The mathematical result of both analysis mean that when using patents versus energy, the scaling coefficient is approximately ' $1 / 4$ '.

When the results of the mathematical analysis and the 'Motion Chart' exercise are gathered, it is also observed that nations where the scaling coefficient drifts in a significant way up or down from ' $1 / 4$ ', the trajectory does not become linear, and oscillations appear in most of the cases. Figure 9 presents a result for four selected nations (Costa Rica, Mexico, South Korea and United Arab Emirates).

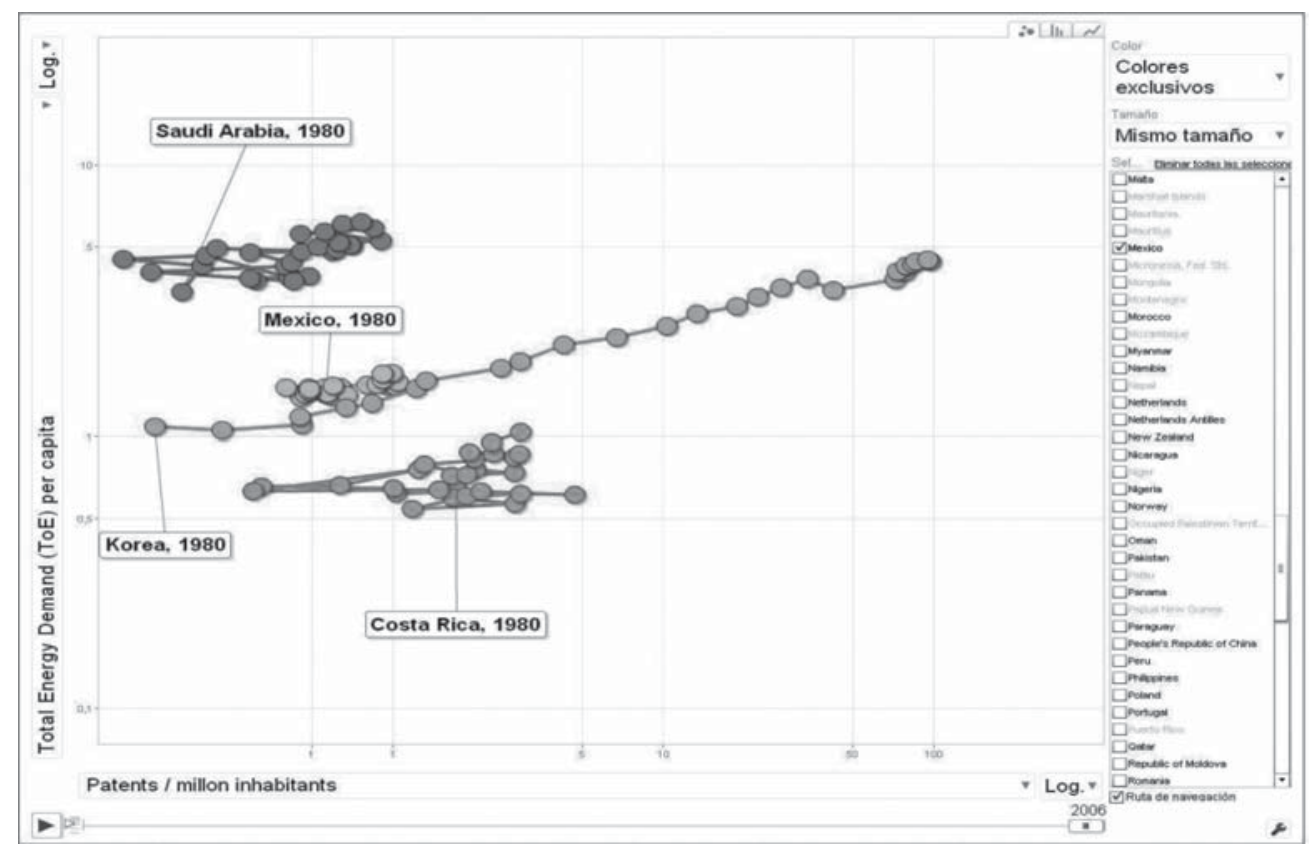

Figure 9: Diachronic analysis (selected countries). Diachronic analysis was made with 'Motion Chart' from Google ${ }^{\circledR}$ Docs (docs.google.com). 


\subsubsection{Energy efficiency and economic development}

It is worth mentioning that concepts like economy of scale, and marginal analysis used in Economics, come from the same principle as the biologic scaling rules: large systems are more efficient, but the costs they generate, including externalities - at some stage - grow faster than the benefits they generate (see Box 2), to the point where obtained additional benefit is lower than the cost increase. An example of probable boundaries and efficiency differentials is observed on the position held by Switzerland and the United States (Table 2).

To conclude this section, it is necessary to highlight that in a closed system like the earth, the non inclusion of externalities to the cost accumulates systemic risks in the form of a reduction of the biospheres' capacity to regenerate resources. In thermodynamic and biological terms, the accumulation of externalities is the accumulation of entropy, which means the consecution of the life expansion directive without balance with the permanence in time directive.

\section{Box 1: Note on energy statistics.}

A nation's energy accounts are based on a document wrongly named 'energy balance', in which origin and destiny of energy is documented. The main requirement purpose of a statement of origin and use of energy 'energy balance' is to generate the identity: supply $=$ demand. This means that in a country where production is lower than demand, the deficit is registered as an import of energy. In countries with surplus, such as the oil exporters, surplus is accounted as an energy export.

The following methodological issues remain unsolved and prevent the exact knowledge of energy availability (restriction level) around the world:

1. The energy used in any manufacturing process of any given country is registered as a domestic consumption, with no exchange account (energy/emissions) to compensate when products are imported or exported. This generates a slant in accounting of countries that may have a higher consumption than the one registered by 'virtual' energy imports, which is received through raw materials and finished goods. The opposite happens to nations that export manufactured and raw materials.

2. In order to make a reliable evaluation on energy availability per capita in each country, it is required to separate metabolized energy by the economic process (transformation loss or inefficiency) from net energy that gets to people's lifestyles. It may happen that a statistical exercise similar to the photographic work made by Peter Menzel (Image 1) can generate better information on energy poverty, economic development, and energy efficiency, than present origin and destiny states of energy 'energy balances'

3. Several governments distort domestic energy markets through subsidies and taxes. In order to know the restriction level that energy represents for a country's inhabitants, it is necessary to document the cost of an energy basket versus people's available income (energy's relative prices).

4. The last non accounted distortion in energy statistics is that of geography, which produces differences in people's energy needs due to heating and cooling of their living spaces

\subsection{Design}

At present, the words design and evolution are used to frame a metaphysical debate between intelligent design and random evolution. This document sets aside the metaphysical debate related to the design 


\section{Box 2: Note on economic scaling.}

In economics, processes' scaling depends on marginal analysis of production and distribution costs, so that size of production units and supply and distribution networks are figured out based on prevailing scaling economies and diseconomies of a market.

Industries mature when the enterprise ecosystem has stable technical levels and production scales. This means cost minimization and sale price maximization in the market or profit maximization

The scaling evolves according to the exchange of signals that are produced through the price system under the economic Law of supply and demand.

Markets where industries handle worldwide supply and distribution chains are calculated - on financial and market aspects - with a logic that does not include high energy costs and the internalization of negative externalities.

Making an analogy with the metabolic biological process, today's economic processes are scaled in such a way that, if the same happened in nature, it would be possible for elephants with a hummingbirds' metabolic rate to exist. This implies that a 4 ton elephant, instead of requiring $500 \mathrm{~kg}$ of food a day, would require $21,000 \mathrm{~kg}$ and would be able to move as lightly and fast as the little bird. Because of that, a small amount of elephants would be enough to devastate an ecosystem and generate mountains of waste in just a few days.

In view of the above, two sustainable development challenges are:

a) Overcoming change reluctance (sunken costs approach) that present economic processes have, since internalization of externalities means incompatibility of scales with existing economic processes due to the size of productive units and the extension of supply and distribution networks.

b) Finding a way for the internalization of externalities that can enable gradual re-scaling of economic processes.

Table 2: Switzerland and USA economic development and energy intensity.

\begin{tabular}{lcc}
\hline Concept & Switzerland & United States of America \\
\hline GDP per capita (USD) & 64,011 & 46,716 \\
Energy demand (ToE) per capita & 3.42 & 7.74 \\
Patents a year/million inhabitants & 246.07 & 267.61 \\
Human development index & 0.960 & 0.956 \\
\hline
\end{tabular}

and focuses on its physical aspect. In other words, it deepens on the mechanisms that affect the process through which human intelligence is mixed with the surrounding environment.

Although design is intuitively related to the liberal arts', manmade culture comes from creative acts. Every creative act, be it philosophical, artistic or industrial, is designed and behind any design effort is a design approach through which, the designer, gathers his capacities: ideas, techniques and desires around restrictions: physical laws, resources, space and energy availability.

Hence, restriction, capacity and Philosophy are coordinated through design and even in our time it remains an intuitive process that comes more from the subconscious than from reason and science. For 
people, the first design approach rises from their conscious or unconscious answers to the following questions.

Table 3: Origin and destiny questions.

\begin{tabular}{lll}
\hline Type of questions & \multicolumn{1}{c}{ Internal world } & \multicolumn{1}{c}{ External world } \\
\hline 1. Origin questions & What are my capacities? & What restrictions am I facing? \\
2. Destiny questions & Can I increase my capacity? & Can I overcome restriction? \\
\hline
\end{tabular}

Around the internal world questions lie the main epistemological issue, courage to know the world. Since knowledge requires an increase in capacity to accumulate negentropy, and this is a costly process in terms of resources, time and effort, some people may have reasons to give up the increase of capacity.

With possible answers to questions in Table 3, people choose a design goal with which they move or stay at: Status quo, Survival, Transformation or Growth. The choice of each design goal implies adopting a set of positions according to:

\subsubsection{Optimization versus maximization}

It has been established on the horizontal dimension of the model's hemispherical analysis that, in metabolic terms, living beings function as follows:

Up (optimization) $\uparrow:$ There is low environmental instability where cooperation prevails over competition; an efficient metabolic arrangement is more important than total metabolic capacity. This design vector will be named 'Optimization', where system variables are arranged to obtain the best result in systemic terms. This is consistent with pursuing: empathy, planning, Ethos, adherence to external law, efficiency, low externality, cooperation, virtue, and common good.

It should be noted that throughout the document Ethos refers to consciousness on the effects that the exercise of will produces in others and in the world, and the importance that the consequences and results have to whoever generated them.

Down (maximization) $\downarrow$ : There is high environmental instability and competition prevails over cooperation while reproductive competition and total metabolic capacity is more important. This design vector will be named 'Maximization'. In it, system variables are subdued to obtain the highest performance of a reference variable. This is consistent with pursuing: apathy, reaction, competition, no ethos, waste, externality, own law, self-interest, and vice (Fig. 10)

\subsubsection{Submission versus freedom}

Regarding the vertical dimension of the hemispherical analysis, the following was established:

Left (submission) $\leftarrow$ : Low capacities to generate negentropy, options are limited. This design vector will be named 'Submission'. Given the low negentropic capacity, the energetic cost to generate an increase in capacity represents an expensive bet in terms of exchange of strategy. Additionally, more value is given to what a person has, than to what can be obtained; this means inability to exchange strategy and derives in: ignorance, disease, acceptance of time/life reduction, low energy use, insecurity, guilt, change and risk reluctance, narrow-mindedness, restrictions.

Right (freedom) $\rightarrow$ : High capacity to generate negentropy creates a wide range of options. The data exchange grows and so does energy use and exchange of entropy with the environment. This 


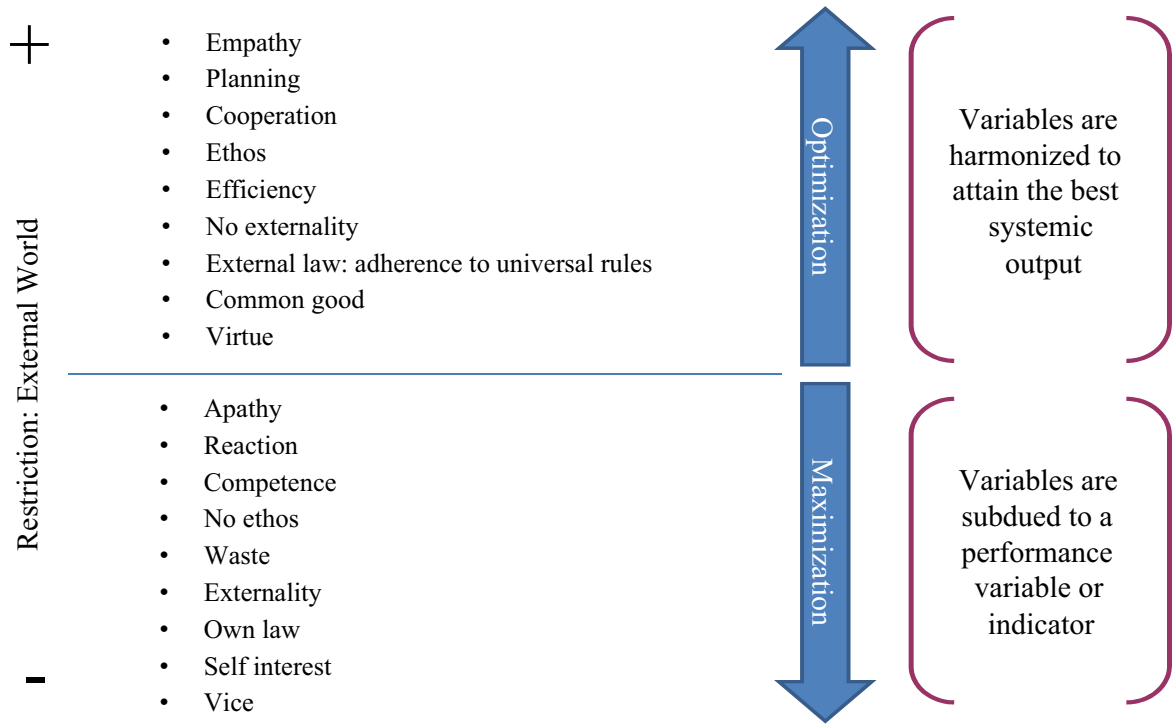

Figure 10: Optimization $\uparrow$ versus Maximization $\downarrow$, the representation shows how behavioural and cultural categories can be organized when using an 'Optimization' perspective or a 'Maximization' perspective.

design vector will be named 'Freedom'. Given the high negentropic capacity, it is easy to make energy investments destined to explore new possibilities. Moreover, it means freedom to evolve according to: knowledge (logos), health, time/life increase, higher energy use, security, responsibility, change and risk acceptance, openness, ideals (Fig. 11).

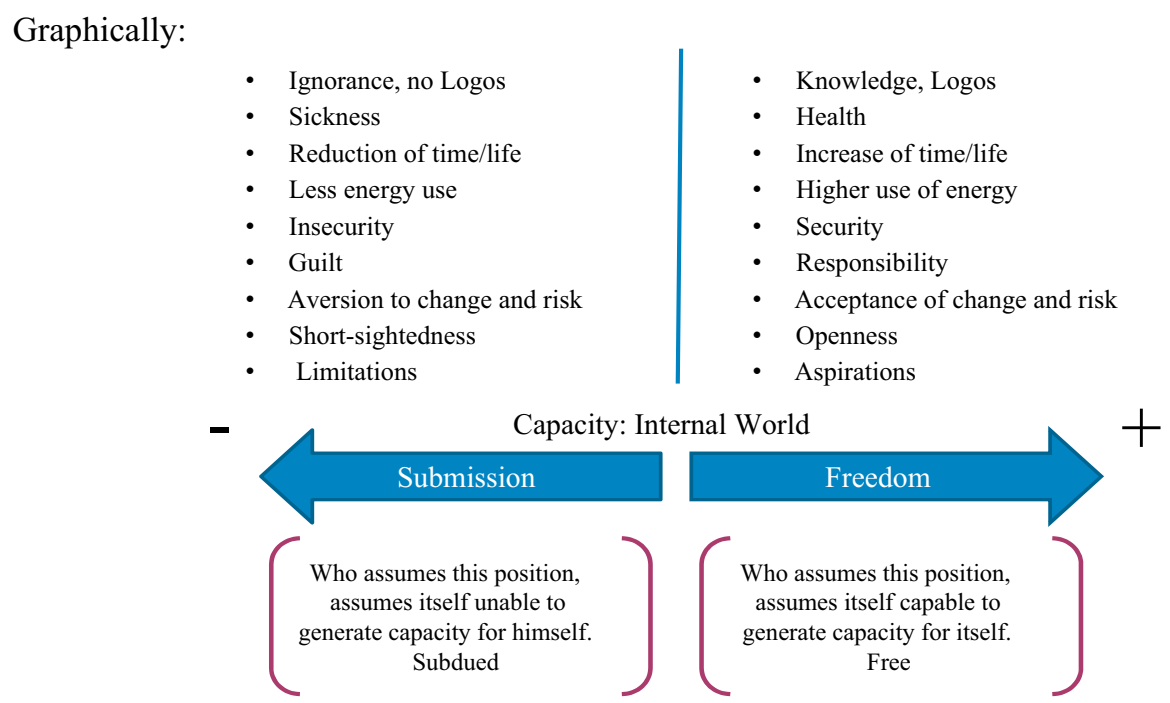

Figure 11: Submission $\leftarrow$ versus freedom $\rightarrow$, shows the representation on how different categories can be arranged around the acceptance of submission or because of the pursuit of freedom. 
Table 4 summarizes the characteristics of the model.

Table 4: Characteristics of the model.

\begin{tabular}{|c|c|c|c|c|}
\hline & \multicolumn{2}{|c|}{ Submission } & \multicolumn{2}{|c|}{ Freedom } \\
\hline & \multicolumn{2}{|c|}{ Survival } & \multicolumn{2}{|c|}{ Transformation } \\
\hline \multirow{12}{*}{ 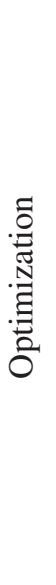 } & Submission: & Optimization: & Optimization: & Freedom: \\
\hline & Ignorance, & Empathy & Empathy & Knowledge, \\
\hline & no $\log o s$ & Planning & Planning & Logos \\
\hline & Disease & Cooperation & Cooperation & Health \\
\hline & Time/life reduction & Ethos & Ethos & Time/life \\
\hline & Lower energy use & Efficiency & Efficiency & increase \\
\hline & Insecurity & No externality & No externality & Higher energy \\
\hline & Guilt & External law: adherence & External law: adherence & use \\
\hline & Change and risk & to universal rules & to universal rules & Security \\
\hline & reluctance & Common good & Common good & Responsibility \\
\hline & $\begin{array}{l}\text { Narrow-mindedness } \\
\text { Restrictions }\end{array}$ & Virtue & Virtue & $\begin{array}{l}\text { Change and risk } \\
\text { acceptance }\end{array}$ \\
\hline & & & & $\begin{array}{l}\text { Openness } \\
\text { Ideals }\end{array}$ \\
\hline \multirow{15}{*}{ 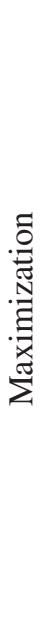 } & \multicolumn{2}{|c|}{ Status Quo } & \multicolumn{2}{|c|}{ Growth } \\
\hline & Submission: & Maximization: & Maximization: & Freedom: \\
\hline & Ignorance, & Apathy & Apathy & Knowledge, \\
\hline & no $\log o s$ & Reaction & Reaction & $\log o s$ \\
\hline & Disease & Competition & Competition & Health \\
\hline & Time/life reduction & No ethos & No ethos & Time/life \\
\hline & Lower energy use & Waste & Waste & increase \\
\hline & Insecurity & Externality & Externality & Higher energy \\
\hline & Guilt & Own law & Own law & use \\
\hline & Change and risk & Self-interest & Self-interest & Security \\
\hline & reluctance & Vice & Vice & Responsibility \\
\hline & Narrow-mindedness & & & Change and risk \\
\hline & Restrictions & & & acceptance \\
\hline & & & & Openness \\
\hline & & & & Ideals \\
\hline
\end{tabular}

\subsection{Evolution of configuration}

Because human culture is part of the evolutionary process, it is necessary to distinguish design from evolution of configuration. At present, the great cultural dilemma circles around what political configuration should a society use. The discussion is focused on two base possibilities [19]:

- Closed society. Within low capacity environments (submission), mechanisms to which people are subdued are favoured. This is consistent with the idea that when people give up capacity growth, 
the environment becomes more dominant over people's behaviour and choices, and they expect the existence of an authority that designs and re-designs the rules.

- Open society. In high capacity (freedom) environments, emerging mechanisms are favoured, where there are few rules and wide operating margins. People expect minimum interference from authority and participation in designing and redesigning the rules.

Earth's inhabitants are under the influence of some authority regime, represented by NationStates; so it is hard to separate design and regulation, since modern states use Law to code design and regulation (configuration) with a single tool.

Since the same mechanism is used to make design and to establish regulation, an identity is created: 'Law is design and design is regulation'. The latter is deeply embedded in modern conception of cultural design. As it was mentioned at the beginning of this chapter, design is the coordination of possibilities and restrictions. In other words, once the design is established, it becomes a frame where a set of interactions can take place, and regulation is the configuration of the design arrangement.

An example of the difference between design and regulation can be seen in money, where design is represented by the rules that generate confidence in people to use money as an exchange means. However, the base design of currency does not determine the price system configuration which is possible by the existence of money, although it affects it. So the authority, without redesigning money, may: (a) interfere in price system through price controls (regulation) or (b) allow price system evolution by letting individual behaviours aggregate through supply and demand interactions.

It must be taken into account that contemporary currency or fiduciary money is a special merchandise whose value depends on the amount of money circulating on the economy (monetary supply), according to the amount of transactions economic agents can carry out (monetary demand), as well as the trust markets have in the monetary authority to keep balance among supply and demand, plus economical expectations perceived in and out of the economy represented by a currency. Also one should consider that in several countries there is autonomy of monetary authority regarding political authority, which prevents regulation and design to be under the responsibility of a single institution. But currency and price systems remain in all cases under design and configuration possibilities of an authority.

Human culture is a dynamic, evolutionary and complex system. As such, it must change its configuration in time to absorb variations in its performing conditions. However, this does not mean that each environment's variation may cause a redesign of the whole, only that configuration parameters within the design must be adjusted; hence, the set of adjustments will be named configuration evolution.

It has been said that human being chooses between capacity growth (freedom) or giving up that possibility (submission), so configuration evolution may be found among two possibilities:

- Bottom Up: When individual's subordination to an authority and regulations focused to determine his behaviour are low and change speed and trust [20] are high. This is a participative process in which authority and society concur.

- Top Down: When individual's subordination to an authority and regulations focused to determine his behaviour are high and change speed and trust are low. The process is non inclusive, only the authority participates.

Table 5 shows the elements that constitute the configuration evolution category, which means identifying: whoever designs, regulation level and change speed. This table shows that when the analysis 
is solely centred on the dimension of configuration evolution, possible designs are out of sight. In consequence, the quadrants of the model are written as design goals to indicate that permanence or change in the quadrants requires the adoption or design of a cultural frame that matches each quadrant's features.

The designer is mentioned because whoever is in charge of this activity also arranges and redesigns from his particular view of the world. So, what starts as a certain type of design, when left under somebody else's responsibility, whose view of the world is different from the one who made the design, will be transformed even on configuration activities, such as the evaluation of the system's performance.

In human culture, unlike biological and physical systems, the plasticity that self-determination of action of people, allows redesigning even at configuration and evaluation levels.

According to this, it must be realized that 'Design' is a project activity; it has a purpose, a beginning and an end. '...A project is always a pro-iectum, something that is launched before us to leave the place we are in, to ascend...' [21]. 'Configuration evolution' is a process activity; it is constant and must be circumscribed to the boundaries of the 'Design'.

\subsection{Ontological design}

Now it is necessary to analyze whether the peculiar features of design and the proposed model are good to build the bridge that links the necessary elements to answer the first question:

'Do human beings meet boundaries in the ontology within their reach by cognitive structures associated to the information perceived in their close relationship with the fundamental laws of life?'

The fundamental blocks with which Philosophy is built are:

- Metaphysics. Within Philosophy, it refers to the research that tries to give an answer to fundamental nature of the being and of the world; it is subdivided into Ontology and Cosmology.

- Epistemology. It refers to knowledge theory: What is known? How is it known? What is knowledge? Why is it known what is known?

- Ethics. It is the behaviour theory over which values that guide people's actions are determined.

- Politics. Process through which groups of people take decisions. Within the classical definition of Politics, Economics and Law are subordinate subsets of it.

By incorporating all previously said to the model (Table 4), the following is obtained:

Table 5: Evolution of configuration.

\begin{tabular}{|c|c|c|c|c|c|c|}
\hline \multirow[b]{2}{*}{ \# } & \multicolumn{4}{|c|}{ Evolution of configuration } & \multirow[b]{2}{*}{ Politics } & \multirow[b]{2}{*}{ Design goal } \\
\hline & Designer & Regulation & $\begin{array}{l}\text { Change } \\
\text { speed }\end{array}$ & Configuration & & \\
\hline 1 & Authority/excluding & High & Low & Top down & Closed & $\begin{array}{l}\text { Status Quo } \\
\text { Survival }\end{array}$ \\
\hline 2 & Society/participative & Low & High & Bottom up & Open & $\begin{array}{l}\text { Transformation } \\
\text { Growth }\end{array}$ \\
\hline
\end{tabular}


Table 6: Building blocks of philosophy and the design goals.

\begin{tabular}{|c|c|c|c|c|}
\hline & \multicolumn{4}{|c|}{ Design goals. } \\
\hline Category & 1. Status Quo & 2. Survival & 3. Transformation & 4. Growth \\
\hline Restriction vector & Maximization & \multicolumn{2}{|c|}{ Optimization } & Maximization \\
\hline Ethics & Self-interest & \multicolumn{2}{|c|}{ Common good } & Self-interest \\
\hline Capacity vector & \multicolumn{2}{|c|}{ Submission } & \multicolumn{2}{|c|}{ Freedom } \\
\hline Epistemology & \multicolumn{2}{|c|}{ Superstition } & \multicolumn{2}{|c|}{ Reason } \\
\hline Politics & \multicolumn{2}{|c|}{ Closed } & \multicolumn{2}{|c|}{ Open } \\
\hline Configuration & \multicolumn{2}{|c|}{ Top down } & \multicolumn{2}{|c|}{ Bottom up } \\
\hline
\end{tabular}

It is necessary to discuss metaphysical selection options within the ontology's aspect, according to the rank of design goals established in Table 6. In order to make this task easier, 'Motivation Theory' will be used [22] to determine what motivates people to act:

- Extrinsic. When a person's motivation comes from the outside; it is the approach of 'Have' (fame, fortune, power). It corresponds to a 'Materialistic' metaphysical approach; what can be obtained from outside or from others.

- Intrinsic. When a person's motivation comes from inside; it is the approach to 'Do' (own merits, satisfaction for a well done task, expertise, discovery). It corresponds to an 'Objectivist' metaphysical approach. What can be obtained on its own.

- Transcendent. When a person's motivation comes from the outcome in someone else, it is the motivation to 'Be' (service, common good, unselfishness). It corresponds to a 'Transcendent' metaphysical approach; what can be generated by one's own existence.

The correspondence with the model is:

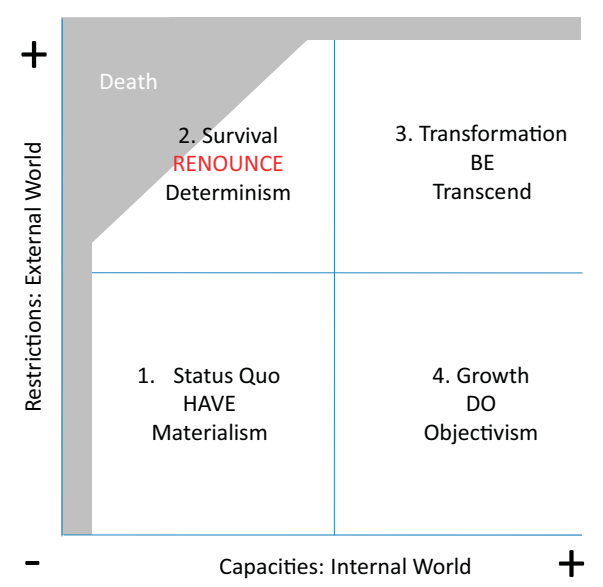

Figure 12: Two additional categories mapped to the model. The possibilities for motivation and the possible ontological approaches. 
Within Fig. 12 (quadrant '2. Survival'), the types of motivation proposed by Pérez López are complemented, saying that in order to remain at the unstable survival subsector, it is necessary to lack of motivation and to adopt a 'Deterministic' metaphysical approach. Nothing else is wanted nor obtained. Trying to move towards the stable 'Death' subsector is self-explanatory of the necessary resignation to motivation.

By supplementing information in Table 6 with the previous comments, Table 7 is obtained.

Table 7: Design goals and motivation.

\begin{tabular}{|c|c|c|c|c|}
\hline & \multicolumn{4}{|c|}{ Design goals } \\
\hline Category & 1. Status Quo & 2. Survival & 3. Transformation & 4. Growth \\
\hline Ontology & Materialism & Determinism & Transcendent & Objectivism \\
\hline Motivation & To have & Renounce & To be & To do \\
\hline Restriction vector & Maximization & \multicolumn{2}{|c|}{ Optimization } & Maximization \\
\hline Ethics & Self-interest & \multicolumn{2}{|c|}{ Common good } & Self-interest \\
\hline Capacity vector & \multicolumn{2}{|c|}{ Submission } & \multicolumn{2}{|c|}{ Freedom } \\
\hline Epistemology & \multicolumn{2}{|c|}{ Superstition } & \multicolumn{2}{|c|}{ Reason } \\
\hline Politics & \multicolumn{2}{|c|}{ Closed } & \multicolumn{2}{|c|}{ Open } \\
\hline Configuration & \multicolumn{2}{|c|}{ Top down } & \multicolumn{2}{|c|}{ Bottom up } \\
\hline
\end{tabular}

\subsection{From biology to philosophy}

The relationship between the laws of Biology, design goals and Philosophy takes place through the following process:

1. Living beings are found in any of four possible metabolic strategies due to the exchanges generated within the relationship between restriction and capacity.

2. Human being's inherent self-determination capacity allows them to choose among:

a. Staying in the quadrant given at birth by cultural and genetic inheritance or;

b. Moving towards a different strategy according to their own evaluation of capacity and restriction.

3. Derived from the decision a design goal is defined through the selection of the design vectors.

a. Internal world: Submission $\leftarrow$ versus Freedom $\rightarrow$

b. External world: Optimization $\uparrow$ versus Maximization $\downarrow$

Once the design goal has been chosen, the ontological approach over which the philosophy of life that will guide existence is adopted (Table 7).

This means that human beings find boundaries in the ontology within their reach, due to cognitive constructions linked to information gathered in their close relationship with the fundamental laws of life. 


\section{DESIGN GOALS AND CULTURAL CHANGE}

\subsection{Need for change}

By and large, philosophical efforts are focused to build unitary philosophies or to oppose a competing one. Under the proposed approach of four design spaces, a set of different philosophies can work given the view points of the practitioners as long as environmental conditions (restriction) and evolutionary genetic and cultural possibilities (capacity) match.

The relationship between practiced philosophy and context is ruled by the perception of quality. For people it is important to evaluate their situation and make plans according to the results obtained through the evaluation process. At every time and era, different indicators have been chosen (e.g. 'please-displease from the gods', or 'GDP per capita'); indicator selection is the bias that show how the world is perceived and, after this selection the quality concept arises, consistency or lack of consistency among practiced philosophy (desire) and environment (reality).

In that scenario, the lack of quality will drive the practitioner to undertake actions that would allow him to restore the function of the context 'change the world', according to a particular perception of what the world must be. From that it would stem that if one's life philosophy is not changed, then the world should be.

Building on this last concept, it is necessary to penetrate into the action mechanisms that produce life strategy changes, and it is pointed out that the act of 'changing the world' is not a push action, but a rearrangement of the world around one's self, which produces serious problems to the person living in an environment resilient to change. People only open to the possibility of change in the practiced philosophy when the environment defeats them.

\subsection{Change movements}

\subsubsection{From submission to freedom}

The movement from submission to freedom is caused by a revolution or change of established order. Revolution is understood here as an increase of capacity with no connotations of destruction, which by definition would generate reduction of order. But it must be accepted that the revolution of a person, many times is perceived by others as an attempt to destroy the world, situation that causes many conflicts among people. This indicates that the genesis of 'revolution' is always a capacity increase in terms of life, health, energy access, knowledge. The opposite movement is regression or restoration of the previous order.

\subsubsection{From optimization to maximization}

The movement from optimization to maximization can originate in two positions: one from the low capacity space and another from the high capacity space.

From low capacity: Aggression = to reduction of restrictions in prejudice of the resources of others. This movement has the implicit recognition of the inability to accomplish something by its own, for example: class struggle, whose foundation act is the ideological appropriation of that belonging to others (production means) and not the construction of something new. The opposite movement is decadence.

From high capacity: Affluence = restriction reduction by intensification in use of environmental resources, for example: industrialization and economic growth through creation of new opportunities due to competition and increased use of resources (metabolic war). The opposite movement is crisis. 
The above is consistent with that pointed out by Carlos de la Isla [23], regarding the existing relationship in man's self-sovereignty conception, behind the economic philosophies that arose from modernity, and some necessary conditions for the existence of post-modernity, proposed by Carlos Llano [24].

\subsection{Technology}

Another aspect to be addressed within the model's explanatory possibilities is technology. It would not be valid to circumscribe ontology and philosophy within it, without doing it for the most tangible expression of cultural evolution.

Generally, the reference to 'science and technology' is used in conjunction to make reference to the design process used in modern economies but it is important to separate both components in order to analyze them.

Stricto senso, science is the path on which man tries to know - or get close to - the truth, be it from an objectivist perspective [25], the most used at present, and even speaking from a theological approach. Nonetheless, it needs to be said that is not inherent for logos, to produce techne or anything that is person-designed and has a concrete manifestation within the world, which is a definition of technology in the widest sense of the word. The only requirement for science is to generate a higher knowledge on the universe. However, knowledge or generation of higher levels of conscience has enabled production of new technologies since remote times.

This relationship allows the creation of composition fallacies, such as the popular belief that says that the steam engine produced the modern era and not all the way around, that the modern man invented a modern way to see the world, which enabled massive incorporation of steam technology to the economic processes.

It is sufficient to state that the know-how to generate motion through water or wind, mechanics and basic concepts to create manufacturing models were known by human kind since ancient times, but technical possibilities generated by understanding of the world, do not imply the widespread use of a technology. They just open the possibility to do it.

The implicit component in the leap among science and technology is purpose, which is a vector composed by will and the ethical approach on what people want to accomplish.

An example of the above is on the knowledge the human kind obtained at the beginning of the 20th century, regarding the fundamental properties of matter and, the energy potential of heavy atoms nuclei splitting.

From this abstract and scientific investigation, two opposed technologies emerged. On one side, scientists that became wicked technologists developed atomic bombs. On the other, scientists that became engineers used the same principles of physics to develop atomic reactors with the ultimate purpose of producing electricity for mankind's benefit. Here engineering can be defined as the synthesis of art and science. It is the design of something new out of the coordination of possibilities and restrictions. Thus, it is possible to obtain more than one technology from the same knowledge, depending on purpose, which is modulated by the ethical approach that guides will towards the outcome.

Consequently, technology is not a goal, but an outcome that is affected by the design goal of its creator. See Fig. 13 for visual schematics.

It is necessary to bear in mind that technology appropriation can only happen if it is done by someone who has compatible knowledge and purpose to internalize and reproduce the outcome. Acquiring a technologically sophisticated object does not mean, for the acquirer, the internalization of technology if it is not capable to penetrate inside the implicit logos and ethos of the object and is willing to run it, maintain it and improve it. 


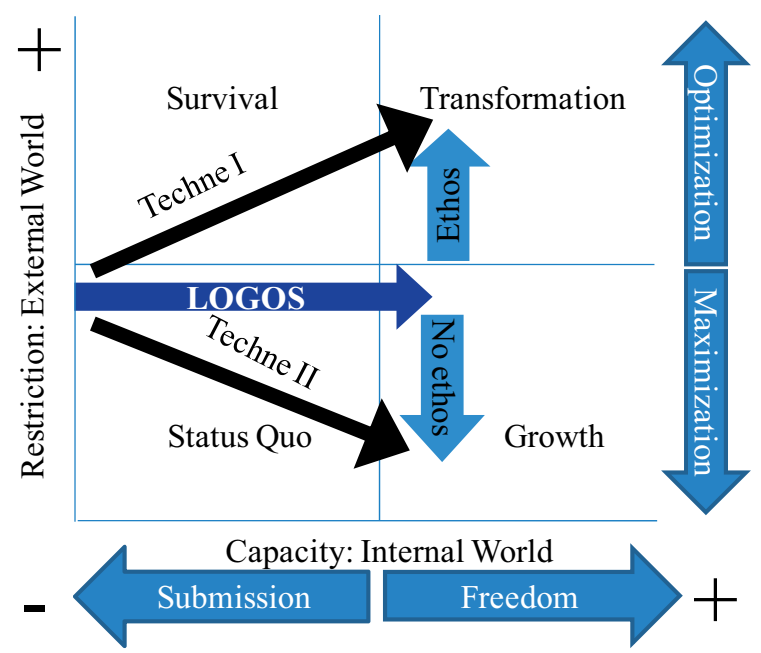

Figure 13: Possibilities for technology. Out of the same level of knowledge different technologies can emerge. The main aspect that changes the type of technology is the intention with which is designed and used.

So, technological transfer from a higher to a lower capacity position is not possible, since it requires the will to increase capacity and thus start a revolution process in order to abandon the 'Survival' or 'Status quo' spaces, as per the case.

\subsection{Politics and rhetoric}

Within the model, several fundamental categories have been addressed: ontology, ethics, epistemology, quality and technology; now it is time to talk about politics and rhetoric. However, it is first necessary to widen our definition on politics in order to point out that politics is understood as the process used to establish the desired and needed relationships between people.

Since each individual lives under different restriction conditions as well as genetic and cultural inheritances, even within a small and homogeneous group of people, difference among individuals can be enough for members to adopt different design objectives. Because the definition of a design objective resides deep within the subconscious as the departure point of the strategy used to face life, the defense of one's own position is crucial to survival. Thus, differences among people can be big enough that there can be no chance of harmonic coexistence among individuals.

Around this issue there is the possibility of an error in the environment's appreciation generated by other person, and a conflict which results in a useless waste of resources and capacities. The human being, at the same time, is driven to defend his vision of the world and to avoid conflict with his peers that either leads to aggression or to an existence with unacceptable life conditions.

In order to do the latter and live with concepts opposite to his beliefs, the person enters a mental status known as cognitive dissonance [26], which is the uncomfortable feeling generated by holding two contradicting concepts simultaneously as true. Although the unpleasant feeling caused by cognitive dissonance drives the individual to solve the dilemma, it is common to use defense mechanisms such as rationalization to evade giving solution to the problem and avoiding by confirming ones own position to get into conflict with others. 
Here is where rhetoric is mixed up with politics because in addition to what was mentioned at the beginning of this chapter, politics also guides the design of coexistence mechanisms according to what people perceive as good, given the ontological identity shared with the group. For many people, quality (correlation between desire and reality) is identical to good. On a maximization perspective, reaching a merit figure, regardless the disproportioned generation of negative externalities, will seem good even if it is not. In the context used here we make reference only to the perception of good, not to good itself.

Rhetoric is only the technique used to explain, in the best possible way, one's own interpretation regarding what is happening and the desired course of action.

As the energy and information levels increase, as well as reference environments vary, the pressure for conflict increases and rhetoric is developed as a substitute of politics. At some point, it becomes a construction tool for cognitive dissonances that make coexistence possible, in spite of the increase of differences between perception and reality or synesthesia.

Looking at the example of modernity used on the technology section, it is easy to see that previous to separating the elements that form technology, the category appeared as a goal that emerged from knowledge placing no relevance whatsoever in who develops it. Moreover, ideas such as the popular belief that the industrial era emerged as a by-product of the steam engine invention, and not from the modern man, is linked to the same issue.

\section{Box 3: Note on projection of cognitive dissonance.}

In order to point out limits, change barriers and complexity, it is usual that language, even academic one, uses figures as: 'it's a political issue', 'it's an institutional issue', 'it's a cultural issue'

However, issues only concern to relationships between people and, thus, one must be careful when using categories such as: politics, institutions and culture among others. This is because the mentioned concepts are cognitive constructions that facilitate the analysis of complex processes, but the grammatical action that gives a proper name to an abstract category does not mean that it can be used as a noun to project the causality of an issue.

Example

Political issues are related to decisions taken by groups: make war, or make peace. Once a group reaches a decision, the political issue fades away.

When the group does not reach a decision, the political issue subsists, even more, if part of the group takes a decision and that causes a new conflict. The latter generates a new political issue that will remain and get complicated as long as the decision processes remain open and mixed with other issues.

Regardless of the fact that human group dynamics can accumulate a great deal of open political issues, in every case, responsibility can be linked to the members of the group or groups involved. The inability to link people to any given situation, but not the lack of will to do it, will point out to the inexistence of a real issue.

However, the inability to face a solution process (reaching a political decision), and possible benefits generated by indecision to some members of a group, will allow the use of a concept like 'politics' in a projective way, making that the cause and responsibility of the issues or problems to be assigned to an analytic abstraction. With this, people:

1. Get rid of their share of responsibility, 'it is all politics' fault'.

2. Solve, if that were the case, the dissonance between a practiced life philosophy and reality, 'I think it is wrong, but that's the way politics works'. 
3. Because it is impossible to summon 'politics' to a negotiation table, the persistence of the issue is guaranteed as something that should be studied and managed permanently.

4. The latter prevents 'the issue' to go back to the point of origin, where responsibility falls on people and where reality can challenge the existing beliefs on the world's inner workings.

A valuable example of paralysis dissolution in a society, by the re-integration of the 'political' responsibility to people, is found within the processes of 'Truth and Reconciliation' organized by Peace Nobel Prize winner, Desmond Tutu in South Africa, when the apartheid fell.

In both cases, phenomena generated by people are depersonalized and converted through rhetoric in metaphysical entities that exist outside of persons and that are used as repositories that can accumulate cognitive dissonances that will not be solved since they do not belong to anybody's inner being (see Box 3).

Hence, politics and the politician are perverted when, through rhetoric, an art is created where the artist manufactures cognitive dissonances that produce designs that do not match any context or philosophy. Furthermore, it is not strange that this design integrity issue rises easier for people with integrity issues, in the worst cases, or naive people in less toxic situations. At the same time, it is possible to do politics with no philosophy and ethics, and useless philosophy that does no good to mankind.

\subsection{Quadrants, political systems characterization and types of design}

Although the formal characterization of a large group of societies requires both profound historical and statistical analyses, the evidence here presented allows for a simple, yet powerful, characterization of different political systems and the related design objectives (Table 8).

Table 8: Characterization of political systems.

+ Survival: ancestral survival cultures, such as Kenya's bushmen and the Amazon's Yanomami. Theological social design

Status Quo. authoritarian systems such as: empires, fiefs, dictatorships, autarchic monarchies and countries rich in natural resources and poor in human development.

। Institutional social design - Capacity
Transformation: there is no explicit political design for this system. Post-industrial market economies' designs that keep a balance between market and social cohesion systems, such as those in Scandinavian nations and Japan, and whose special feature is the persistence in modern culture of concepts like 'Lagom', 'Jante's Law' and 'Shinto', can be considered close to this type of system. Transformational social design

Growth: several of the western capitalist economies known as developed countries, recently BRIC nations (Brazil, Russia, India, China). Competitive social design 
Linked to what was said in the characterization of quadrant 'Transformation', we find the ideas explored by some of the main theological systems that aim to the pursuit of truth, freedom, perfection, and a ethical behaviour to reach the balance produced by virtue. Nonetheless, there is no political system design that contains a theory of man with which a design of transformational social technologies (economics and law) can be made possible.

Nevertheless, while preparing this paper, the research showed that a 'Transformational' design based on metabolic flow systems. 'Metabolic Design' or 'Metabolic Economy', a subject not addressed in depth in this paper, can be described in a subsequent work.

\subsection{Design goals and differences in social design}

Regarding the question 'How are the design goals people use affected?' The proposed model allows an integral analysis comprised four design approaches and the philosophies that align them with each design objective. The latter is made in connection with fundamental laws of life and enables us to size the depths that separate each of their practitioners (Table 9).

Table 9: Design objectives and types of design.

\begin{tabular}{|c|c|c|c|c|}
\hline & \multicolumn{4}{|c|}{ Design objectives } \\
\hline Category & 1. Status Quo & 2. Survival & 3. Transformation & 4. Growth \\
\hline Ontology & Materialism & Determinism & Transcendent & Objectivism \\
\hline Motivation & To have & Renounce & To be & To do \\
\hline Restriction vector & Maximization & \multicolumn{2}{|c|}{ Optimization } & Maximization \\
\hline Ethics & Self-interest & \multicolumn{2}{|c|}{ Common good } & Self-interest \\
\hline Capacity vector & \multicolumn{2}{|c|}{ Submission } & \multicolumn{2}{|c|}{ Freedom } \\
\hline Epistemology & \multicolumn{2}{|c|}{ Superstition } & \multicolumn{2}{|c|}{ Reason } \\
\hline Politics & \multicolumn{2}{|c|}{ Closed } & \multicolumn{2}{|c|}{ Open } \\
\hline Configuration & \multicolumn{2}{|c|}{ Top down } & \multicolumn{2}{|c|}{ Bottom up } \\
\hline Design & Institutional & Theological & Metabolic & Competitive \\
\hline
\end{tabular}

Additionally, the tensions produced by the interaction among groups that build social technologies from different ontological positions are identified, as well as the possibility of change only when the environment defeats individuals (Fig. 14).

From the latter stems that it will be more likely to start a change of strategy when a human group is self-perceived in a survival situation and once the possibility of change appears there are two alternatives:

- Revolution of capacities, getting out of the problem by developing higher capacity, or

- Aggression, reducing restriction by appropriation of somebody else's resources. 


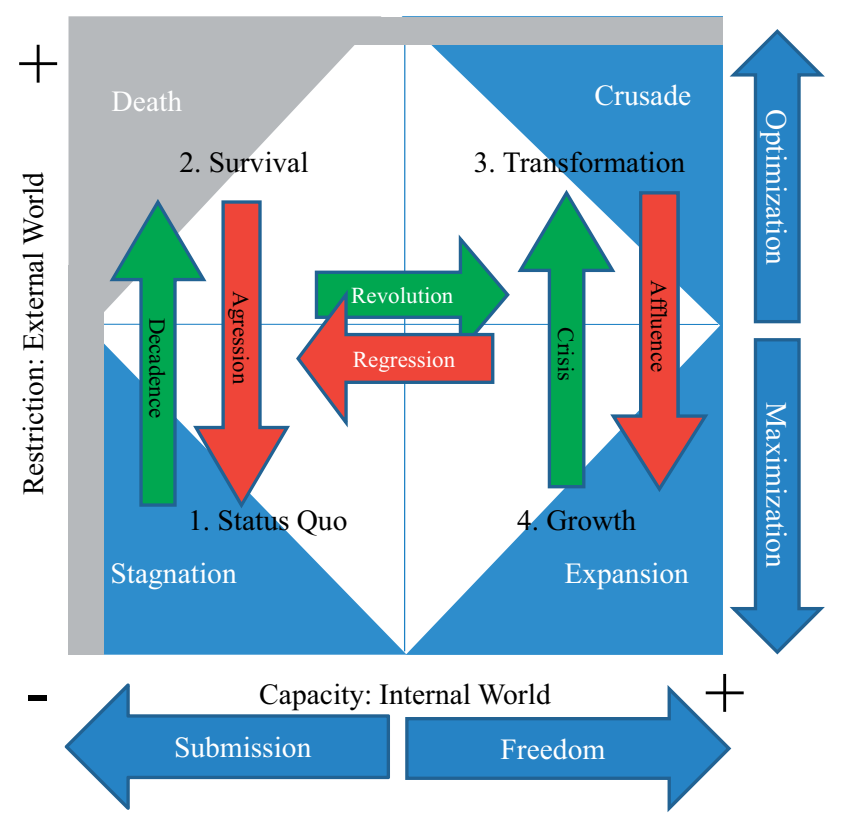

Figure 14: The complete graphical representation of the model. It contains the quadrants, its subsectors, the design vectors 'submission versus freedom', 'optimization versus maximization' and the change movements or possibilities. It must be noted that this graphical representation is only visual metaphor that aids the understanding of the model.

It can be stated that there is a third possibility of change when a society placed on quadrant ' 3 . Transformation' changes the optimization perspective for a maximization one or, as it was discussed above, initiation of a metabolic war, situation to be approached in the next section due to its characteristics.

\section{CONCLUSIONS}

\subsection{Telos}

Human kind's cultural evolution, though short on a perspective of the whole of evolution, is rich in diversity of experiences. It first developed in the survival sector, as demonstrated by anthropology in the analysis of ancestral societies. As knowledge level grew and new technologies allowed access to other energy sources, designs based on tradition and authority were viable, until the emergence at the Renaissance of the vertiginous and persistent Modern Era where change is constant [27].

Modern era's success on capacity growth is beyond dispute and, as proven by the reduction of authoritarianism at the end of the 20th Century, an economic system that metabolizes resources as fast as capitalism does, in the long term, also allows us to think about an affluent and open society. However, evidence indicates that the economic metabolism generated by the human kind has overcome the recovery capacity of the biosphere several decades ago, because less crop lands, fresh water, clean air, and energy are available, while needs increase due to population growth and cultural evolution.

In addition, personal income maximization demands that time investment, that is, existence itself, becomes a 'working for a living and living for working' experience, which implies the virtualization 
of family and friendship bonds. This phenomenon is linked to pathologies of evasion of reality and to the inadequate transmission of cultural inheritance towards the new generations, and to the reproduction of patterns of violence and self-destruction among people.

In spite that around a billion people [28] have access to high levels of energy, health and knowledge, the rest of humanity, in decreasing gradients, live on higher restriction and knowledge environments (Figs 5 and 6). It is from this difference that confrontation among people emerges and prospers in an increasing scale, and whose foundations have been explained before.

Possibilities are still open. A part of the world claims for the return to the ancestral roots. Energyrich countries poor on culture are passive, and developed nations that are moving forward on the path of quick economic growth try to solve the dissonance produced by the need of economic growth under the known model versus facing higher levels of restriction and instability.

Up to this moment, the promise to achieve a sustainable development is placed on the hope that 'politics', 'institutions', 'efficiency', 'governments', and not people, will reduce the exhaustion rate of key resources and will overcome growing boundaries through 'technology'.

At the end of the day, population projections [29] indicate that by year 2050 there will be eight to ten billion people over the earth. This means by following current trends (Fig. 15), the return to low consumption models will only happen if either a reduction of population and/or rationing of resources by restoration of authoritarian regimes occur (follow the permanence directive). By that token, freedom of action generated by open systems would not be possible. In fact, famine and upheavals would provoke a favourable environment for a regression to authoritarianism firsthand around low capacity contexts.

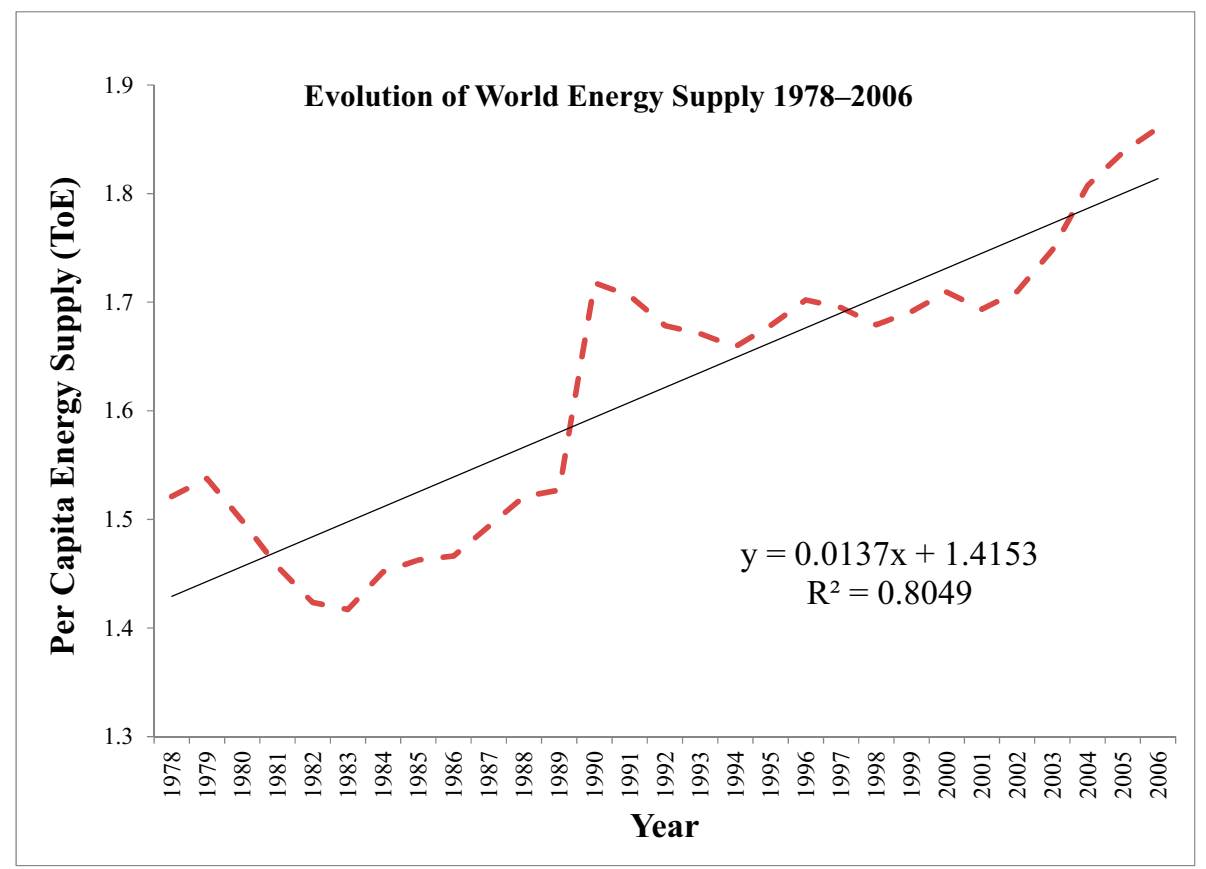

Figure 15: The per capita evolution of energy supply (consumption) from 1978 to 2006. The regression equation given shows that the long-term yearly positive growth rate is $1.37 \%$. Source: International Energy Agency (www.iea.org). 
It is worth retaking the statistical exercise shown in Fig. 7 to include the democracy index [30]. In Fig. 16, the democracy index is represented through the change of the bubbles diameter. The larger the bubble, the fuller the democracy people live within the shown country. Table 10 is made by obtaining average value of the democracy index, grouped by energy scales.

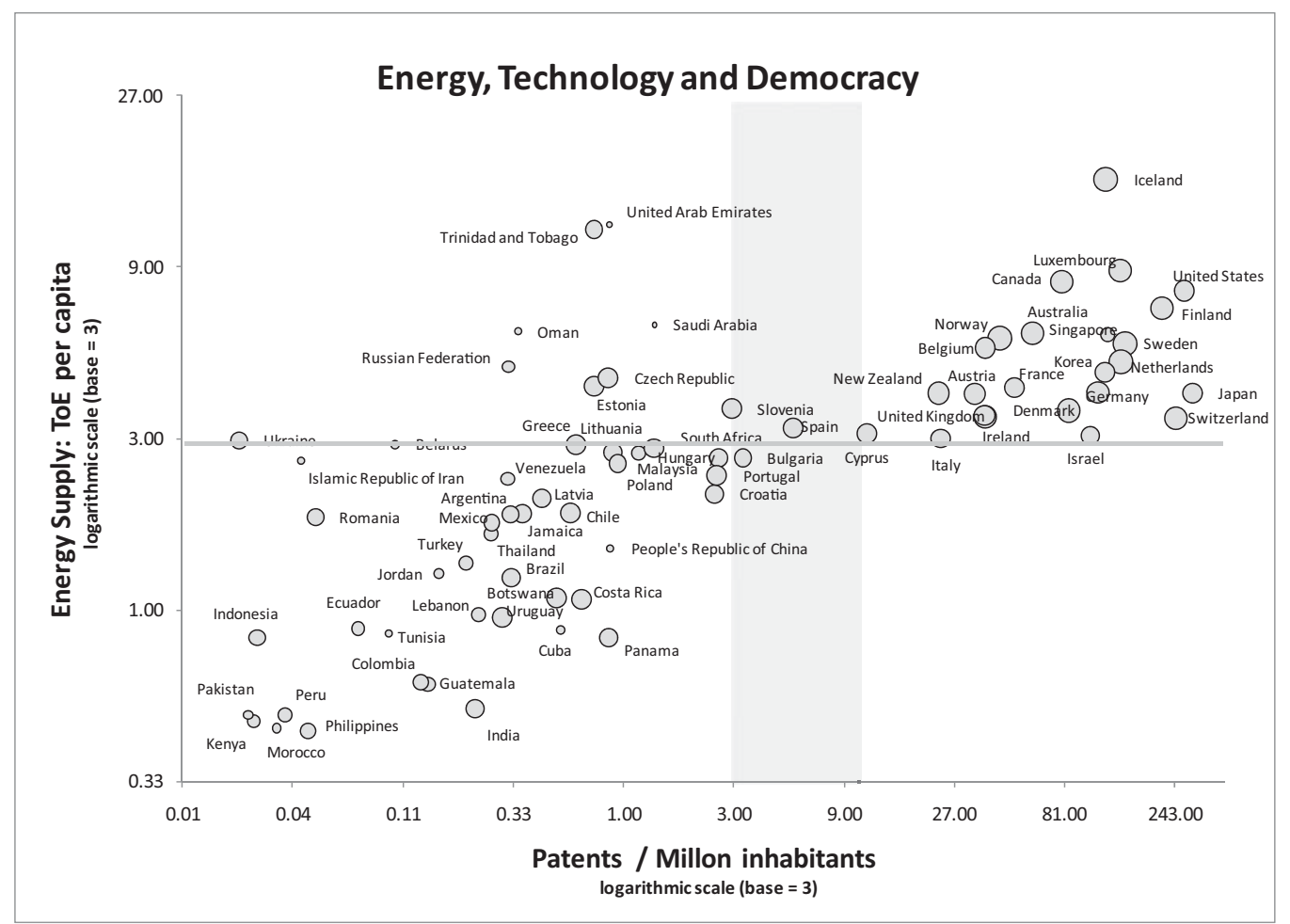

Figure 16: Energy, technology and democracy in this figure is similar to Figs 7 and 8, but adds the Democracy Index 2007 (diameter of the bubbles) published by The Economist Intelligence Unit to show how technology development and freedom are related. This relation is further explained in Table 10.

Two outcomes, linked to the model, derive from the above. On one side, the idea that development, energy and freedom are related is strengthened. On the other side, it seems unlikely to keep the existence of open political systems when the energy incorporation to people's lives is low, as can be seen on scales one and two of Table 10, and neither when there is no balance between energy abundance and cultural development (see Fig. 17).

Due to the above, and even if new environmental and energy technologies can manage the current adverse horizon, remaining within the 'growth' quadrant will not be possible, given that sooner or later the energy restriction will be reached again. Because the eternal peddler, mentioned by economists to describe man's unlimited ability to need something else once a need has been covered (following the expansion directive), will find uses for any new energy source and the generation of a cycle among affluence and crisis, which are the change movements at high capacity sectors on the 
Table 10: Energy intensity and democracy.

\begin{tabular}{|c|c|c|c|c|c|c|}
\hline$\#$ & $\begin{array}{l}\text { Scale } \\
(\mathrm{ToE})\end{array}$ & $\begin{array}{c}\text { Total } \\
\text { countries }\end{array}$ & $\begin{array}{c}\text { Democracy } \\
\text { index average }\end{array}$ & Regime type & $\begin{array}{c}\text { Example } \\
\text { countries } \\
\text { (democracy) }\end{array}$ & $\begin{array}{c}\text { Human } \\
\text { development } \\
\text { index average }\end{array}$ \\
\hline 1 & $0-1$ & 44 & 4.69 & Hybrid & $\begin{array}{l}\text { Ethiopia } 4.72 \\
\text { Burundi } 4.51\end{array}$ & 0.632 \\
\hline 2 & $1.01-3$ & 28 & 6.35 & $\begin{array}{l}\text { Distorted } \\
\text { democracy }\end{array}$ & $\begin{array}{c}\text { Colombia } 6.40 \\
\text { Macedonia } 6.33\end{array}$ & 0.823 \\
\hline 3 & $3.01-10$ & 31 & 7.75 & $\begin{array}{l}\text { Distorted } \\
\text { democracy }\end{array}$ & $\begin{array}{l}\text { Taiwan } 7.82 \\
\text { Estonia } 7.74\end{array}$ & 0.930 \\
\hline \multirow[t]{2}{*}{4} & $>10.01$ & 3 & 6.43 & $\begin{array}{l}\text { Distorted } \\
\text { democracy }\end{array}$ & $\begin{array}{c}\text { Philippines } 6.48 \\
\text { Indonesia } 6.41\end{array}$ & 0.903 \\
\hline & Total & 106 & 6.07 & $\begin{array}{l}\text { Distorted } \\
\text { democracy }\end{array}$ & Guatemala 6.07 & 0.778 \\
\hline
\end{tabular}

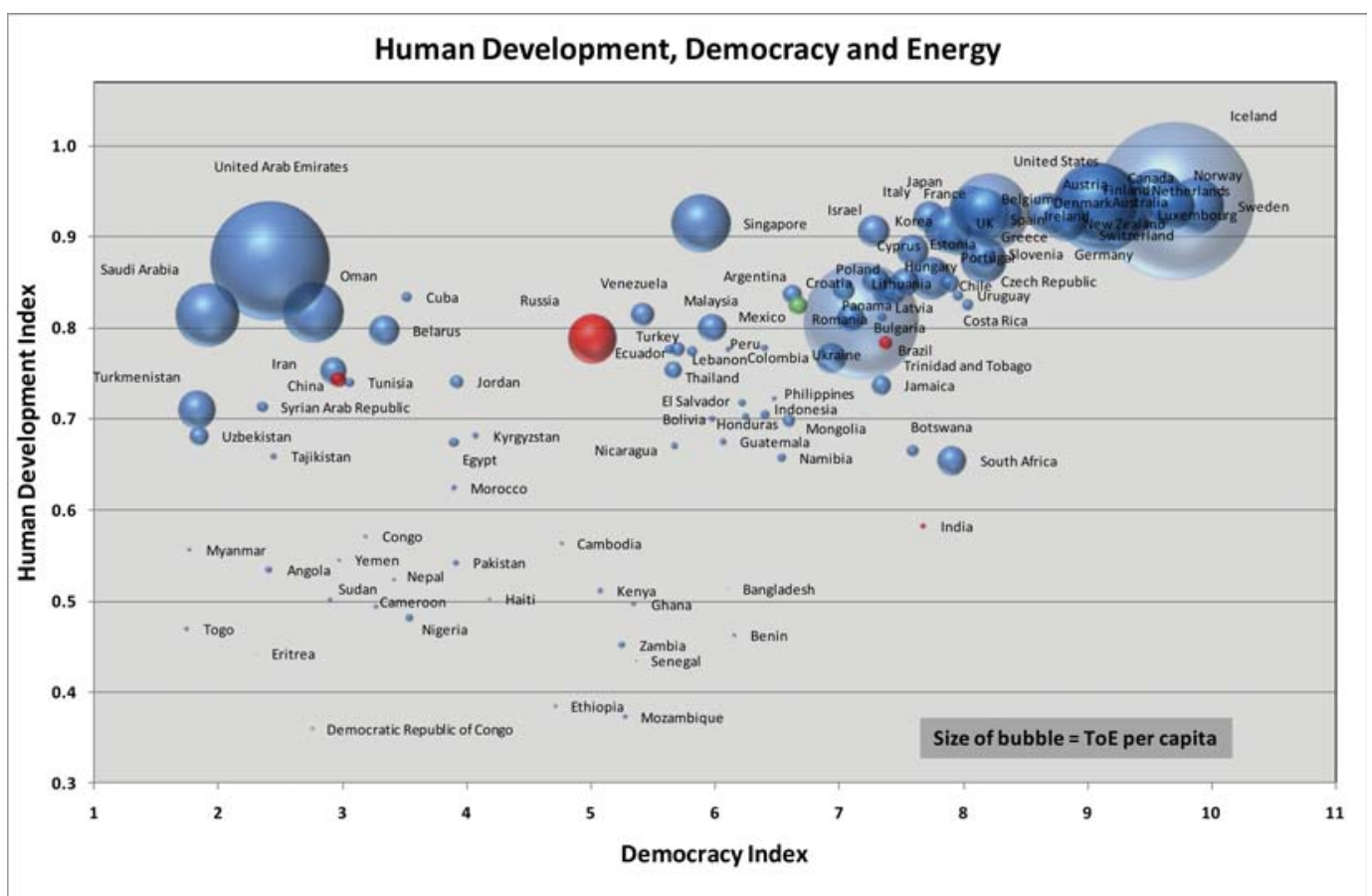

Figure 17: The relation between the Human Development Index 2007 (HDI), United Nations Development Programme (www.undp.org), The Economist Intelligence Unit Democracy Index 2007 and the per capita Total Energy Demand measured in Tons of Oil Equivalent (ToE). The data show two different development routes. One where the Democracy Index is very low, energy use is high and where HDI can get over 0.8 but does not surpass 0.9 . The second route is the one where Democracy Index is high, energy consumption is high but lower for equivalent development levels than the first development path and where several countries achieve a HDI higher than 0.9 . 
model (Fig. 14), will be inevitable. This gets reinforced by Albert Einstein's postulate $E=\mathrm{mc}^{2}$, that means that accelerating an object demands exponential amounts of energy up to the limit represented by light speed. For minor scales, such as space travels and universe exploration, vehicles require to reach escape velocity equal to $11.2 \mathrm{~km} / \mathrm{s}$. Which means that future energy and efficiency needs will multiply.

In Economics, this recurrence is described as an economic cycle and it is important to point out that as the affluence stage is greater, crisis also become deeper and more destructive due to the risk accumulation on over scaled economic systems. Translated to a concept coined during the last world financial crisis, 'too big to fail' [31] is the inefficiency measure of a system and of the systemic risk that makes it unstable. This instability issue represents the main failure of contemporary economic systems.

In biotechnology, there is a similar example where it has not been possible to overcome a barrier when genetically modified organisms used to maximize the return on products with economical value, obtained from harvests and fermentation, within few generations revert to a homeostatic genetic and metabolic condition.

In both cases, biology and economy, the greater the maximization, that is, the subordination of all variables to a performance figure, the higher the crisis to return to a stable evolution path. Two biological examples, among many, are found in: (a) domestic cows, which by artificial selection, produce milk in such quantities that if they are not milked twice a day, do not have a chance to revert to a condition of stability and die, and (b) corn, which also by the domestication process that has undergone, lost all necessary features to naturally spread its seeds.

It can be said that life, in spite of existing in an inhospitable universe whose entropy grows by the minute, tries through all possible means, to support the evolution process by rising negentropic capacity via an increase of conscience or accumulation of knowledge. And persist in time up to the limit that energy availability and entropy will allow. The same applies to the human being.

\subsection{Functional social designs}

When addressing the question: 'What design approaches would be functional?' We have that low capacity (Survival and Status Quo) environments are temporary shelters when possibilities to increase capacity are low, or when freedom decrease or regression happen; within these strategies time can be earned, but capacity increase, evolution and freedom are given up, which happens in prejudice of attaining life's second directive (expansion).

The growth environment is consistent with the directive to increase order generation and information, but high metabolic rates deplete resources faster than knowledge to acquire new capacity, so continuity probabilities diminish.

In consequence, the path where expansion and permanence in time are balanced is on the transformation quadrant. Nevertheless, that design goal has only been explored by theology and lacks the political and philosophical designs that can allow modern man's cognitive transformation into postmodern man. In other words, reconciling man's freedom with universal laws that rule him.

To pretend that post-modernism can be invented by the man with a modern mind set, or that longs for Status Quo or a return to the original state, and even for the one who mixes design philosophies, is dissonant. All designs arise from an ontological position, so the first requirement is the existence of the post-modern humans that design the post-modernism in which they want to live.

It is just now that the need to articulate a transformational world appeared. The history of the human being describes the road of a blind man who by trial and error discovers gradually the ontological spaces that are within the reach of his experience. It is only when he discovers the possibilities 
and experiences what surrounds him that he acquires a chance to choose what he wants according to what he is.

Thereby it makes sense to do more research about metabolic design. When thinking about a probable change of era for the human kind, where it may be possible to reconcile logic and intuition, science and theology, conscience and the subconscious, philosophy and politics, image and reality, over a design, articulated by the tangible elements life works for; freedom (logos) and optimization (ethos) as the telos life tries to reach.

\subsection{Boundaries and design requirements for a transformational world}

\subsubsection{Design boundaries}

At the end of the day the world created by the human kind, is based on the use of fragmented visions by people pertaining to different contexts and by the massive use of a design objective that is not adequate for a world without unlimited resources.

Throughout this paper we have discussed the limits that define biological and cultural design, and now it is very useful to have a better understanding of the design rules present at nature, for life's processes as well as for non-living systems.

Mathematical relations on the subject, such as Fibonacci's series, have been known for centuries. This series indicate correspondence between numbers and proportions on a great number of natural structures. However, this kind of data has been collected as interesting occurrences and only recently an engineering principle has been proposed. Through it, is possible to explain the design that takes place in nature. This principle or theory is called Constructal Theory [32], which states:

- 'For a finite-size (flow) system to persist in time (to live), its configuration must evolve such that it provides easier and easier access to its currents.'

- 'Every system is destined to remain imperfect (it will have restrictions), so it is necessary that the design of the system comes from the homogeneous distribution of the restriction.'

Important engineering progress has been achieved with the constructal design approach to develop systems with optimal performance in terms of persistence and efficiency (see http//www. constructal.org). Furthermore, now there is an explanation on the allometric laws that define the borders of biological design, such as the mentioned Kleiber's Law, which represents millions of years of evolutionary experimentation.

\subsubsection{Design requirements}

There is one last question to be answered in order to conclude this work: what would be the design requirements? This document has provided an explanation on the possible ontological designs and the conclusions were that for three out of the four possibilities, there are philosophies, political technologies and implementation experiences. However, there is a gap regarding the necessary political technology to build a world, or culture, or coexistence deal among people, within the transformational design objective. Hence, here are some design requirements for transformational social technologies:

In order to shape political technologies: (a) integrated, that cover law and economy; (b) evolutionary, free or with low regulation and (c) consistent with the transformation quadrant of the model, it is necessary that the design:

- Does not generate incentives to non-cooperation (1)

- Internalizes the cost of social and environmental externalities (2) 
- Frees restrictions so that motives (ethics) and not incentives (instinct) become the dominant mechanism for social regulation (1)

- Aligns image and reality (2)

- Reduces the distance on the capacity contexts in which people develop in order to decrease differences within the design objectives they use (3)

- Widens the free flow of the information and knowledge streams (culture) (4)

- Produces a governance model by design and coordination and not government through regulation (4) (Fig. 18).

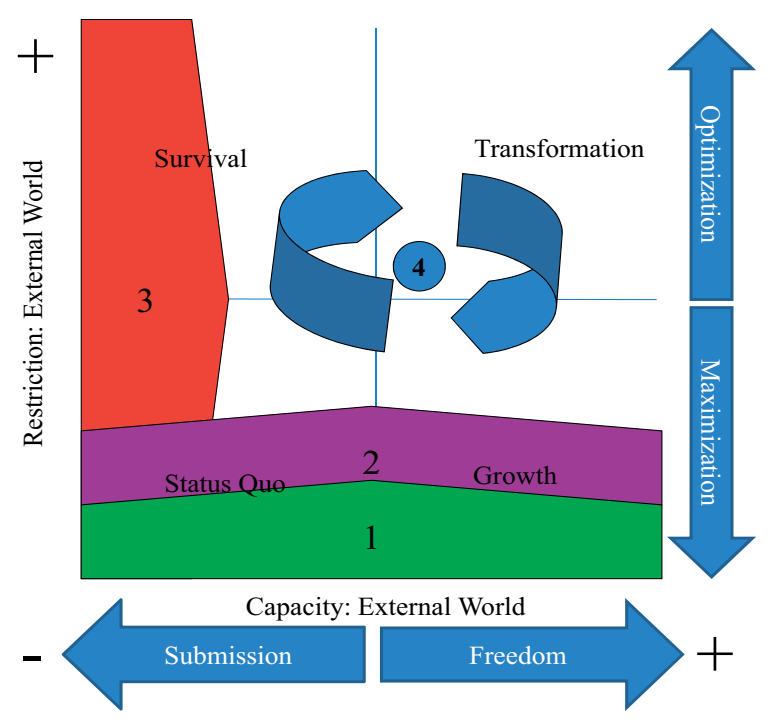

Figure 18: The environment where 'transformational' social technologies can evolve requires that that several problems of contemporary societies be addressed: 1. Elimination of incentives for non-cooperation, 2. Internalization of externalities, 3. Difference reduction on the capacity contexts people experience, 4 . Widen the flow for the information and knowledge streams.

\section{GLOSSARY}

Autotroph. Living beings that produce their own means to survive, vegetables.

Commoditization. It refers to the dilution of the differentiation of a product in a market, and that allows consumers to make purchase decisions based solely on price. It implies a constant market price reduction.

Design goals. For our purpose 'design goals' are defined as the group of elements that guide any design effort. It can be understood as the substrate over which creativity and motivation develops.

Diachronic. Related to time.

Downstream. It refers to any place out of the influence of the transaction.

Ecological niche. Position of a species in relation to others within an ecosystem.

Environmental instability. For a population, environmental instability is generated by sudden climatic variations, plague recurrence, diseases and ecological competition. 
Ethology. Discipline that studies animals' behaviour.

Externality. It is an outcome whose benefit (positive externality) or cost (negative externality) falls back on a third party that is outside the transaction of origin.

Fecundity. Amount of gametes generated by a reproductive cycle that correlates positively with the fertility rate.

Fibonacci's series. It is the numerical series where the next number is obtained by adding the two previous numbers. It is also the series that gave origin to the golden rule of proportion in arts and design: $0,1,1,2,3,5,8,13$.

Heterotroph. Living beings that feed on other living beings.

Homeostasis. It is the feature of an open or closed system, especially in a live organism, through which the internal environment is regulated in order to maintain a stable and constant condition.

Jante's Law. Concept coined in 1933 by Askel Sandermose, who compiles shared concepts form Scandinavian people, aligned to the principle of Lagom, and is presented through the narrative of a novel that describes life in a small Danish village (Jante) at the beginning of the 20th century.

Kleiber's Law. The metabolic Scaling Law discovered by Max Kleiber points out that the metabolic rate of an animal is mass raised to a power of $3 / 4$ and 1 for plants and vegetation.

Lagom. It has no literal translation and means, not too much, not too little, it is a philosophy of life from folk Swedish culture. Why should one want more than enough?

Second Law of Thermodynamics. The amount of entropy of any thermodynamic isolated system tends to increase over time.

Shinto. Ancient cultural and religious root from Japan centred in harmonic relationship with nature an guided by a sense of collaboration among people, that is characteristic of Japanese culture.

Subconscious. It is understood as a conscious level beneath the self-realized consciousness. It is not known that one is thinking.

Synesthesia. Unusual phenomenon where a person, when receiving a stimulus through a sense, shows manifestations in another one, for example, when listening to music, colour lights are seen. In our time, the distance between image and reality produces synesthesia (e.g. using drugs is pleasant for the user, but destroys the person).

System (Retrieved from Wikipedia, 2009). Set of real or abstract entities that interact or are interdependent and make an integrated whole.

ToE (Ton of oil Equivalent). International Energy Agency's standardized unit which is equal to the amount of energy that would be obtained through the combustion of a ton of crude oil. It is equal to: $41.868 \mathrm{GJ}$ and to $11.63 \mathrm{MW} / \mathrm{h}$.

UNFCCC (United Nations Framework Convention on Climate Change). Within the United Nations Organization, the country members reunited in Rio de Janeiro, in June 1992, agreed to establish the United Nations Framework Convention on Climate Change, whose constituent goal has not been accomplished.

Virtual. Denotes something that is perceived real, but it isn't.

\section{REFERENCES}

[1] Enkvist, P., Nauclér, T. \& Rosander, J., A cost curve for greenhouse gas reduction. The Mckinsey Quarterly, 4(1), 2007.

[2] Kaku, M., Visions: How Science Will Revolutionize the 21st Century, Anchor Books: New York, pp. 3-19, 1997.

[3] Zaltman, G., Marketing Metaphoria, Harvard Business Press: Boston, pp. 47-61, 2008.

[4] Zaltman, G., How Customers Think, Harvard Business Press: Boston, pp. 65-71, 2003.

[5] Nielsen, P., A new molecule of life. Scientific American, December 2008. 
[6] Rubí, M., Does nature break the second law of thermodynamics? Scientific American, October 2008.

[7] Wikipedia, www.wikipedia.org/negenthropy, online June 10, 2009.

[8] Brillouin, L., Negentropy. Journal of Applied Physics, 24(9), pp. 1152-1163, 1953. doi:http://dx.doi.org/10.1063/1.1721463

[9] Kleiber, M., Body size and metabolic rate. Physiological Reviews, 27, pp. 511-541, 1947.

[10] Pianka, E., On r and K selection. American Naturalist, 104, pp. 592-597, 1970. doi:http://dx.doi.org/10.1086/282697

[11] Darwin, C., The Origin of Species, John Murray: London, 1859.

[12] Shermer, M., Darwin misunderstood. Scientific American, p. 34, February 2009. doi:http://dx.doi.org/10.1038/scientificamerican0209-34

[13] Kropotkin, P., Mutual Aid: A Factor of Evolution, Forgotten Books: London, (Conclusion), 1902.

[14] Liebig, J., Familiar Letters on Chemistry, John Gardner: London, p. 60, 1844.

[15] Kauffman, S., The Origins of Order: Self Organization and Selection in Evolution, Oxford University Press: New York, pp. 643-646, 1993.

[16] Teilhard, P., The Phenomenon of Man, Evergreen Review: New York, p. 429 (e-book location), 2009.

[17] International Energy Agency (IEA), World Energy Outlook 2008, IEA: Paris, pp. 386-388, 2006.

[18] United Nations Development Programme (UNDP). www.undp.org

[19] Popper, K., The Open Society and Its Enemies, Routledge: London, 1945.

[20] Zak, P., The neurobiology of trust. Scientific American, pp. 62-67, June 2008.

[21] Llano, C., Función, Plan y Proyecto. Tópicos, 10, pp. 25-59, 1996.

[22] Pérez, J., Liderazgo y Ética en la Dirección de Empresas, Deusto: Madrid, 1998.

[23] De la Isla, C., De la perplejidad a la utopía, ITAM: Mexico, pp. 133-152, 1998.

[24] Llano, C., Sistemas Versus Persona, McGraw Hill: Mexico, pp. 1-35, 2001.

[25] Rand, A., Atlas Shrugged, Penguin Group: New York, 1957.

[26] Festinger, L., A Theory of Cognitive Dissonance, Stanford University Press: California, 1957.

[27] Heilbroner, R. \& Thurow, L., Economics Explained, Simon \& Schuster: New York, pp. 11-25, 1998.

[28] Stern Review on the Economics of Climate Change; HM Treasury, U.K. Economic Service, Online, www.hm-treasury.gov.uk/sternreview_index.htm

[29] World Population Estimate; United States Census Bureau, International Database, Online, www.census.gov/ipc/www/idb/worldpopinfo.php

[30] The 2007 Index of Democracy; The Economist, Intelligence Unit, Online, www.economist. com/media/pdf/democracy_index_2007_v3

[31] Watts, D., Too big to fail? How About Too Big to Exist?. Harvard Business Review, p. 16, June 2009.

[32] Bejan, A. \& Lorente, S., Constructal theory of generation of configuration in nature and engineering. Journal of Applied Physics, 1004, 2006.

\section{FURTHER READING}

\section{COGNITIVE SCIENCES}

Ariely, D., Are We in Control of Our Own Decisions?, TED.com, Online, www.ted.com/talks/lang/ eng/dan_ariely_asks_are_we_in_control_of_our_own_decisions.html

Lakoff, G., Don't Think of an Elephant!, Chelsea Green Publishing Co.: White River Junction, 2004. Zaltman, G., How Customers Think, Harvard Business Press: Boston, 2003. 
Damasio, A., Looking for Spinoza: Joy, Sorrow, and the Feeling Brain, Harcourt Inc.: Orlando, 2003.

Zaltman, G., Marketing Metaphoria, Harvard Business Press: Boston, 2008.

Lakoff, G., Moral Politics: How Liberals and Conservatives Think, University of Chicago Press: Chicago, 2002.

Lakoff, G., Moral Politics, YouTube.com, Online, UCTelevision, Online, www.youtube.com/ watch? $=5$ f9R9MtkpqM

Pink, D., The Surprising Science of Motivation, TED.com, Online, www.ted.com/talks/lang/eng/ dan_pink_on_motivation.html

Royal School of Arts (RSA), The Surprising Truth about What Motivates Us, RSA, Online, www. youtube.com/watch?v=u6XAPnuFjJc

\section{PHILOSOPHY}

De la Isla, C., De la Perplejidad a la Utopía, ITAM: Mexico, 1998.

Popper, K., The Open Society and Its Enemies, Routledge: London, 1945.

Teilhard de Chardin, P., The Phenomenon of Man, Evergreen Review: New York, 1955.

\section{ENERGY \& TECHNOLOGY}

Chen, J., A Warm Embrace that Saves Lives, TED.com, Online, www.ted.com/talks/lang/eng/jane_ chen_a_warm_embrace_that_saves_lives.html

International Energy Agency (IEA), Energy Statistics Manual, IEA: Paris, 2004.

Kamkwamba, W., How I Harnessed the Wind, TED.com, Online, www.ted.com/talks/lang/eng/ william_kamkwamba_how_i_harnessed_the_wind.html

Raymond, M. \& Leffler, W., Oil \& Gas Production in Nontechnical Language, Penn Well Corporation: Tulsa, 2005.

International Energy Agency (IEA), World Energy Outlook 2010, International Energy Agency: Paris, 2010.

\section{EVOLUTION, POLITICS, CULTURE \& HISTORY}

Diamond, J., Collapse: How Societies Choose to Fail or Succeed, Penguin Group: New York, 2005.

Diamond, J., Guns, Germs \& Steel, W. W. Norton \& Company: New York \& London, 1999.

Johanson, D. \& Wong, K., Lucy's Legacy: The Quest for Human Origins, Harmony Books: New York, 2009.

Rosling, H., On Global Population Growth, TED.com, Online, www.ted.com/talks/lang/eng/ hans_rosling_on_global_population_growth.html

Kaku, M., Visions: How Science Will Revolutionize the 21st Century, Anchor Books: New York, 1997.

\section{ECONOMICS \& BUSINESS}

Heilbroner, R. \& Thurow, L., Economics Explained, Simon \& Schuster: New York, 1998.

Levitt, S. \& Dubner, S., Freakonomics: A Rouge Economist Explores the Hidden Side of Everything, Harper Collins: New York, 2006.

Becker, S. \& Murphy, K., Social Economics: Market Behaviour in a Social Environment, Harvard University Press: Cambridge, 2000.

Caplan, B., The Myth of the Rational Voter, Princeton University Press: Oxford, 2007. 


\section{COMPLEXITY}

Bejan, A. \& Merkx, G. (eds), Constructal Theory of Social Dynamics, Springer: New York, 2007. Wolfram, S., Computing a Theory of Everything, TED.com, Online, www.ted.com/talks/lang/eng/ stephen_wolfram_computing_a_theory_of_everything.html

Bejan, A. \& Lorente, S., Design with Constructal Theory, John Wiley \& Sons: Hoboken, 2008. doi:http://dx.doi.org/10.1002/9780470432709

Kauffman, S., The Origins of Order: Self Organization and Selection in Evolution, Oxford University Press: New York, 1993. 